\title{
Numerical modeling of blowing and drifting snow in Alpine terrain
}

\author{
Peter Gauer ${ }^{*}$ \\ Eidgenössisches Institut für Schnee- und Lawinenforschung, Flüelastrasse 11, CH-7260 Davos Dorf, Switzerland
}

\begin{abstract}
In mountainous regions, snow transport due to wind significantly influences snow distribution and, as a result, avalanche danger. A physically based numerical two-layer model is developed to simulate blowing and drifting snow in Alpine terrain. One layer describes the driving-wind field and the transport in suspension. The description is based on the atmospheric boundary-layer equations, using an $e-\epsilon$ model for the turbulent closure. The second layer describes the transport due to saltation, including erosion and deposition of snow. Here, conservation equations for mass and momentum are formulated for the mixture of snow and air. Particle trajectory calculations are used to parameterize quantities characterizing the saltation layer. Both layers are mutually coupled by boundary conditions. A two-way coupling between particles and airflow is taken into account. Comparisons between simulation results and field measurements around an Alpine crest show encouraging results.
\end{abstract}

\section{NOTATION}

$\boldsymbol{A} \quad$ Off-diagonal matrix coefficients $\left(\mathrm{m}^{-3} \mathrm{~s}^{-1}\right)$

$A_{i}^{\langle k\rangle} \quad$ Area vector pointing in the direction $k\left(\mathrm{~m}^{2}\right)$

$A^{\langle 3\rangle} \quad$ Top area of the saltation layer $\left(\mathrm{m}^{2}\right)$

$A^{\langle 6\rangle} \quad$ Surface area $\left(\mathrm{m}^{2}\right)$

c Volumetric concentration (1)

$c_{\mu}, c_{1 \epsilon}, c_{2 \epsilon}$ Empirical constants

C Convection coefficient $\left(\mathrm{m}^{-3} \mathrm{~s}^{-1}\right)$

$C_{\mathrm{D}} \quad$ Drag coefficient (1)

$C_{\mathrm{p}} \quad$ Specific heat at constant pressure for moist air

$$
\left(\mathrm{J} \mathrm{kg}^{-1} \mathrm{~K}^{-1}\right)
$$

d Displacement height $(\mathrm{m})$

$d_{\mathrm{P}} \quad$ Grain diameter $(\mathrm{m})$

dd Wind direction $\left(^{\circ}\right)$

$D \quad$ Diffusion coefficient $\left(\mathrm{m}^{-3} \mathrm{~s}^{-1}\right)$

$e \quad$ Instantaneous turbulence kinetic energy $\left(\mathrm{m}^{2} \mathrm{~s}^{-2}\right)$

$E \quad$ Sublimation rate $\left(\mathrm{kg} \mathrm{m}^{-2} \mathrm{~s}^{-1}\right)$

$E_{\mathrm{B}} \quad$ Bonding energy $(\mathrm{J})$

$E_{\mathrm{D}} \quad$ Dissipated energy $(\mathrm{J})$

$E_{\mathrm{E}} \quad$ Kinetic energy of an ejected grain $(\mathrm{J})$

$E_{\mathrm{I}} \quad$ Kinetic energy of an impacting grain $(\mathrm{J})$

$E_{\mathrm{R}} \quad$ Kinetic energy of a rebounding grain $(\mathrm{J})$

$f_{\mathrm{c}} \quad$ Coriolis parameter $\left(\mathrm{s}^{-1}\right)$

$F_{\text {DW }} \quad$ Force of the particle-air interaction (N)

$g \quad$ Acceleration due to gravity $\left(\mathrm{m} \mathrm{s}^{-2}\right)$

$h_{\mathrm{s}} \quad$ Saltation layer height $(\mathrm{m})$

HN New-snow depth $(\mathrm{m})$

HS Snow depth $(\mathrm{m})$

$I_{i} \quad$ Vector of the net radiation $\left(\mathrm{W} \mathrm{m}^{-2}\right)$

$J_{\text {cae }} \quad$ Aerodynamic particle entrainment $\left(\mathrm{kg} \mathrm{s}^{-1}\right)$

$J_{\text {cd }} \quad$ Particle deposition rate $\left(\mathrm{kg} \mathrm{s}^{-1}\right)$

$J_{\text {ce }} \quad$ Total particle entrainment rate $\left(\mathrm{kg} \mathrm{s}^{-1}\right)$

* Present address: Norwegian Geotechnical Institute, Sognsveien 72, N-0806 Oslo, Norway.
$J_{\text {cej }} \quad$ Particle ejection rate $\left(\mathrm{kg} \mathrm{s}^{-1}\right)$

$J_{\text {cs }} \quad$ Settling rate due to gravity $\left(\mathrm{kg} \mathrm{s}^{-1}\right)$

$J_{\text {ct }} \quad$ Turbulent entrainment rate $\left(\mathrm{kg} \mathrm{s}^{-1}\right)$

$J_{\mathrm{m}} \quad$ Horizontal mass-transport rate $\left(\mathrm{kg} \mathrm{s}^{-1}\right)$

$J_{\mathrm{pr}} \quad$ Precipitation rate $\left(\mathrm{kg} \mathrm{s}^{-1}\right)$

$L_{\mathrm{p}} \quad$ Latent heat $\left(\mathrm{J} \mathrm{kg}^{-1}\right)$

$M \quad$ Wind speed $\left(\mathrm{m} \mathrm{s}^{-1}\right)$

$N_{\text {EpI }} \quad$ Number of ejected grains per impact (1)

$N_{\mathrm{I}} \quad$ Number of impacts per second $\left(\mathrm{s}^{-1}\right)$

$p \quad$ Pressure $(\mathrm{Pa})$

$P_{\mathrm{R}} \quad$ Rebound probability (1)

$p_{0} \quad$ Reference pressure $(\mathrm{Pa})$

$q_{\mathrm{L}} \quad$ Humidity (non-vapor part) $\left(\mathrm{kg}_{\text {water }} \mathrm{kg}_{\text {air }}{ }^{-1}\right)$

$q_{\mathrm{T}} \quad$ Total humidity $\left(\mathrm{kg}_{\text {water }} \mathrm{kg}_{\text {air }}{ }^{-1}\right)$

$Q \quad$ Mass flux $\left(\mathrm{kg} \mathrm{m}^{-1} \mathrm{~s}^{-1}\right)$

$r \quad$ Mixing ratio $\left(\mathrm{kg}_{\text {water }} \mathrm{kg}_{\text {dry air }}{ }^{-1}\right)$

$r_{\mathrm{L}} \quad$ Liquid/solid water mixing ratio $\left(\mathrm{kg}_{\text {water }} \mathrm{kg}_{\text {dry air }}{ }^{-1}\right)$

$r_{\text {sat }} \quad$ Saturation water mixing ratio $\left(\mathrm{kg}_{\text {water }} \mathrm{kg}_{\text {dry air }}{ }^{-1}\right)$

$R_{\mathrm{a}} \quad$ Gas constant of dry air $\left(\mathrm{J} \mathrm{K}^{-1} \mathrm{~kg}^{-1}\right)$

$S_{q_{\mathrm{T}}} \quad$ Moisture source term $\left(\mathrm{kg}_{\text {water }} \mathrm{kg}_{\text {air }}{ }^{-1} \mathrm{~s}^{-1}\right)$

$t \quad$ Time $(\mathrm{s})$

$t_{\mathrm{E}} \quad$ Travel time of an ejected grain ( $\mathrm{s}$ )

$t_{\mathrm{R}} \quad$ Travel time of a rebounding grain (s)

$T \quad$ Temperature $(\mathrm{K})$

$T_{\mathrm{V}} \quad$ Virtual temperature $(\mathrm{K})$

$u_{h_{\mathrm{s}_{i}}} \quad$ Wind velocity at the saltation-layer height $\left(\mathrm{m} \mathrm{s}^{-1}\right)$

$u_{i}, u_{j} \quad$ Vector of the wind velocity $(u, v, w)\left(\mathrm{m} \mathrm{s}^{-1}\right)$

$U_{\mathrm{I}} \quad$ Impact speed of a grain $\left(\mathrm{m} \mathrm{s}^{-1}\right)$

$U_{P_{i}} \quad$ Vector of the particle velocity $\left(\mathrm{m} \mathrm{s}^{-1}\right)$

$U_{\varrho_{i}} \quad$ Vector of the relative velocity $\left(\mathrm{m} \mathrm{s}^{-1}\right)$

$V \quad$ (Control) volume $\left(\mathrm{m}^{3}\right)$

$V_{\mathrm{P}} \quad$ Volume of a single grain $\left(\mathrm{m}^{3}\right)$

$W_{\mathrm{f}} \quad$ Particle free-fall velocity (absolute value) $\left(\mathrm{m} \mathrm{s}^{-1}\right)$

$x_{i}, x_{j} \quad$ Represents $(x, y, z)$ for $i=(1,2,3), j=(1,2,3)$

$z_{0} \quad$ Aerodynamic roughness length $(\mathrm{m})$

$\alpha \quad$ Angle $\left(^{\circ}\right)$ 
$\delta_{i j} \quad$ Kronecker delta

$\epsilon \quad$ Dissipation rate $\left(\mathrm{m}^{2} \mathrm{~s}^{-3}\right)$

$\epsilon_{i j k} \quad$ Alternating unit tensor

$\Theta \quad$ Potential temperature $(\mathrm{K})$

$\kappa \quad$ von Kármán constant

$\nu \quad$ Kinematic viscosity $\left(\mathrm{m}^{2} \mathrm{~s}^{-1}\right)$

$\nu_{\mathrm{T}} \quad$ Turbulent kinematic viscosity $\left(\mathrm{m}^{2} \mathrm{~s}^{-1}\right)$

$\nu_{\Theta} \quad$ Molecular thermal viscosity $\left(\mathrm{m}^{2} \mathrm{~s}^{-1}\right)$

$\rho_{\mathrm{a}} \quad$ Density air $\left(\mathrm{kg} \mathrm{m}^{-3}\right)$

$\rho_{\mathrm{d}} \quad$ Density dry air $\left(\mathrm{kg} \mathrm{m}^{-3}\right)$

$\rho_{\mathrm{P}} \quad$ Grain density $\left(\mathrm{kg} \mathrm{m}^{-3}\right)$

$\sigma_{\mathrm{e}}, \sigma_{\mathrm{T}}, \sigma_{\epsilon}$ Empirical constants

$\tau_{\mathrm{a}} \quad$ Airborne shear stress $(\mathrm{Pa})$

$\tau_{\mathrm{g}} \quad$ Grain-borne shear stress $(\mathrm{Pa})$

$\tau_{h_{\mathrm{s}}} \quad$ Shear stress at the height $h_{\mathrm{s}}(\mathrm{Pa})$

$\tau_{i j} \quad$ Shear stress/Reynolds stress $(\mathrm{Pa})$

$\phi \quad$ Slope angle $\left({ }^{\circ}\right)$

$\zeta, \xi, \lambda, \varsigma$ Parameters in the saltation layer parameterization

\section{Subscripts}

()$_{\mathrm{E}} \quad$ Ejected particle

() Impacting particle

() $\quad$ Particle quantity

() $\quad$ Reference quantity

()$_{\mathrm{R}} \quad$ Rebounding particle

\section{INTRODUCTION}

In Alpine terrain, redistribution of snow by wind is a major factor in snowpack evolution as well as in the formation and effectiveness of avalanches. Thus, it is of great interest to predict snow redistribution and its influence on avalanche danger with regard to avalanche forecasting and land-use planning.

Avalanche warning on a regional scale requires information on the occurrence of snowdrift and on the (new-) snow distribution on a mesoscale (several $10 \mathrm{~km}^{2}$ ). Scarcity of land resources is a major restricting factor in the economic development of many mountain villages. In these villages, avalanche danger often causes restrictions on land use. As great interest exists in using all available land resources, efforts are made to develop numerical avalanche models to reliably determine endangered zones. These models require highly resolved input data on the snow-mass distribution in avalanche release zones (microscale; several $100 \mathrm{~m}^{2}$ ) which depends strongly on snowdrift. In both cases, one is interested in suitable tools to assess, analyze or forecast the effect of blowing and drifting snow in Alpine topography. Corresponding to World Meteorological Organization (WMO) standard observations, the term drifting snow is used to describe the near-surface wind transport, whereas the expression blowing snow is reserved for situations where particles rise to a height of $1.8 \mathrm{~m}$ and above. However, in the following the term drifting snow or wind transport will be used to refer synonymously to both phenomena.

The snowdrift model presented here is based on many previous field studies of snow transport as well as on physical and numerical simulations for aeolian particle transport. The field studies show that snow transport is basically given by the transport in saltation and in suspension (Kobayashi, 1972; Radok, 1977; Takeuchi, 1980; Schmidt, 1982, 1986; Mellor and Fellers, 1986). These studies were carried out on plains and aimed at determining the transport rate for steady-state conditions. The attained empirical formulations show that transport rate is proportional to a power of the wind speed, where the power varies typically between 2 and 4 . Only a few attempts have been made to measure snowdrift in mountain areas (e.g. Föhn, 1980; Schmidt and others, 1984; Meister, 1987) where drift flux measurements were made on a crest. Föhn and Meister (1983) also measured the spatial distribution of snow in the area surrounding a crest. Similar measurements were made by Castelle (1995) for a mountain pass. Physical simulations have been used to study the deposition patterns around obstacles (e.g. Iverson, 1980; Anno, 1985) or have dealt with particular features of the drift process (e.g. the particle-bed impact as studied by Maeno and others (1979, 1985, 1995), Willets and Rice (1985), Rice and others (1995, 1996) and Nishimura and others (1998). Numerical models of snow or sand drift differ widely in scope and focus. Specific processes have been studied, for example, simulating the grain impact (Werner and Haff, 1988) or particle transport in saltation (Anderson and Haff, 1988, 1991; Werner, 1990; McEwan and Willets, 1991; Sørensen, 1991). Also models based on heuristic rules for avalanche forecasting have been developed, like ELSA (Mases and others, 1995).

Most transport models for snow can be classified into two categories: Eulerian-Lagrangian (e.g. Sato and others, 1997; Sundsbø and Hansen, 1997) or Eulerian-Eulerian (Uematsu and others, 1989; Liston and others, 1993). However, Masselot and Chopard (1998) follow a different approach, using a lattice Boltzmann model. Particle tracking, which is done in the Eulerian-Lagrangian approach, can require large computational effort and restrict the application of those models to small areas (e.g. the estimated number of particles in the saltation layer is about $\left.1-5 \times 10^{6} \mathrm{~m}^{-2}\right)$. All the models discussed above are two-dimensional. More recent models address the requirements of three-dimensional transport modeling (Liston and Sturm, 1998; Naaim and others, 1998). These models are Eulerian-Eulerian. Common to most transport models is the separation between saltation and suspension. Either the transport rate for suspension is defined by a height integration of the flux with given profiles for the wind speed and concentration (Pomeroy, 1989; Liston and Sturm, 1998), or a separate balance equation for the particle concentration is solved (Uematsu, 1993; Naaim and others, 1998). The assumption that the wind profile develops fully into a logarithmic profile over the total height of the suspension layer, which Pomeroy (1989) and Liston and Sturm (1998) take for granted, is critical in Alpine terrain. For example, measurements (Föhn, 1980) show that the wind profile on a crest is very different from a logarithmic profile. This difference also affects the concentration profile. Almost all descriptions of the transport in saltation (e.g. Pomeroy, 1989; Uematsu, 1993; Liston and Sturm, 1998; Naaim and others, 1998) rely on Pomeroy's (1989) empirical formulation, which is defined for steady-state conditions. Pomeroy and Gray (1990) assume that it takes about 300-500 $\mathrm{m}$ for a boundary-layer flow that is approximately $3 \mathrm{~m}$ in depth to reach steady conditions. In Alpine terrain, with its high variability, $300-500 \mathrm{~m}$ is a long distance. Castelle (1995) pointed out that the drift transport seldom if ever reaches steady state in mountainous terrain. Recently, attempts have been made to parameterize the deviation from steady state (Liston and Sturm, 1998; Naaim and others, 1998).

Due to the limited range of applicability because of the simplifications that were used, the above models cannot accurately represent complex topographies like an Alpine terrain and non-steady wind fields. To overcome some of 
the weaknesses of the previous models, the model presented here uses a different approach for the description of saltation. Based on particle motion, a continuum formulation is derived for the saltation layer. This formulation includes deposition and erosion, distinguishing between aerodynamic entrainment and particles ejected due to impact, and does not require steady-state conditions.

\section{NUMERICAL MODEL}

Blowing and drifting snow is strongly related to the atmospheric boundary layer (ABL). Erosion, transport and deposition of snow depend on the wind field and the turbulence within the lowest $10-100 \mathrm{~m}$ of the boundary layer, the socalled surface layer (SL). It is widely accepted that the primary transport mechanisms are saltation and suspension. The transport due to saltation usually starts at light wind speeds, $M_{10}=5-8 \mathrm{~m}^{-2}$, where $M_{10}$ is the wind speed at $10 \mathrm{~m}$ (Schmidt, 1980; Castelle, 1995; Li and Pomeroy, 1997). Typical transport rates (integrated over the height) range from 0.001 to $0.03 \mathrm{~kg} \mathrm{~m}^{-1} \mathrm{~s}^{-1}$ (Takeuchi, 1980; Castelle, 1995). Saltation is usually restricted to a vertical extension of about $0.01-0.1 \mathrm{~m}$ (Kobayashi, 1972), and drift densities range from 0.1 to $1 \mathrm{~kg} \mathrm{~m}^{-3}$ (Mellor and Fellers, 1986; Pomeroy and Gray, 1990; Castelle, 1995). For comparison, even if the transition from saltation to suspension is more or less continuous, noticeable suspension starts at moderate wind speeds $\left(M_{10}=7-11 \mathrm{~m}^{-2}\right)$, depending on the particle size and flow turbulence. An estimation of the required shear velocities is given in Gauer (1999). The typical mean grain-size in drifting snow is about 150-200 $\mu \mathrm{m}$ (Schmidt, 1984; Pope, unpublished). Transport rates for suspension range from 0.01 to $0.1 \mathrm{~kg} \mathrm{~m}^{-1} \mathrm{~s}^{-1}$ and drift density is $<1 \mathrm{~kg} \mathrm{~m}^{-3}$ (Mellor and Fellers, 1986; Castelle, 1995). The vertical extension can reach several tens of meters, though the drift density usually decreases significantly with increasing height above the surface.

For a review of current conceptual understanding of aeolian particle transport, the reader is referred to Anderson and others (1991) or McEwan and Willets (1993). In a greatly simplified form, one can imagine the transport due to blowing and drifting snow as follows (see also Fig. 1): If the wind blowing over a snow surface becomes sufficiently strong, and wind shear exceeds a certain critical value, the so-called threshold, some grains are set in motion by the wind. Initially, only a few of these will be lifted off the surface and accelerated by the wind. Some of them will gain enough energy to rebound and/or eject other grains on impact. At the onset, the number of grains resulting from an impact, the so-called mean replacement capacity, is more than one on average. This results in an exponential increase of grains in the saltation layer, which follow more or less ballistic trajectories determined by the time-averaged wind profile. Grains within the saltation layer are not - or only weakly - influenced by turbulence of the wind. As more and more grains saltate, the vertical wind profile changes due to the considerable extraction of momentum from the airflow by the grains in motion. Now the grains gain less energy, and the probability of a grain rebounding and/or ejecting other grains on impact decreases until the mean replacement capacity reaches the equilibrium value of one. At this stage, the number of saltating grains fluctuates around a certain value, sometimes called the saturation value, which depends on the driving-wind field and certainly on the properties of the snow surface. The surface properties determine the fluid threshold as well as rebound and dislodgements effected by collisions of grains with the surface, and thus play an important role in saltation. In turbulent and gusty winds, a certain number of particles will be caught by eddies and will travel a significantly greater distance without surface contact. The ratio between mass transport by suspension and mass transport by saltation increases with increasing wind speeds and turbulence. In all cases, gravity counteracts the wind forces on the grains in saltation and suspension.

In short, wind transport can be regarded as the result of five closely/mutually linked processes:

aerodynamic entrainment,

grain trajectories,

grain-snowpack impacts,

modification of the wind field,

transport due to turbulent suspension.

In the following, a numerical model is proposed that uses a continuum mechanical approach to describe blowing and drifting snow, and makes use of a splitting of the two dominant transport processes into two mutually coupled layers. This procedure is chosen to reduce the computational effort, which would drastically increase if the saltation layer was to be fully resolved. The transition mode between saltation and suspension, the so-called modified saltation, is not separately

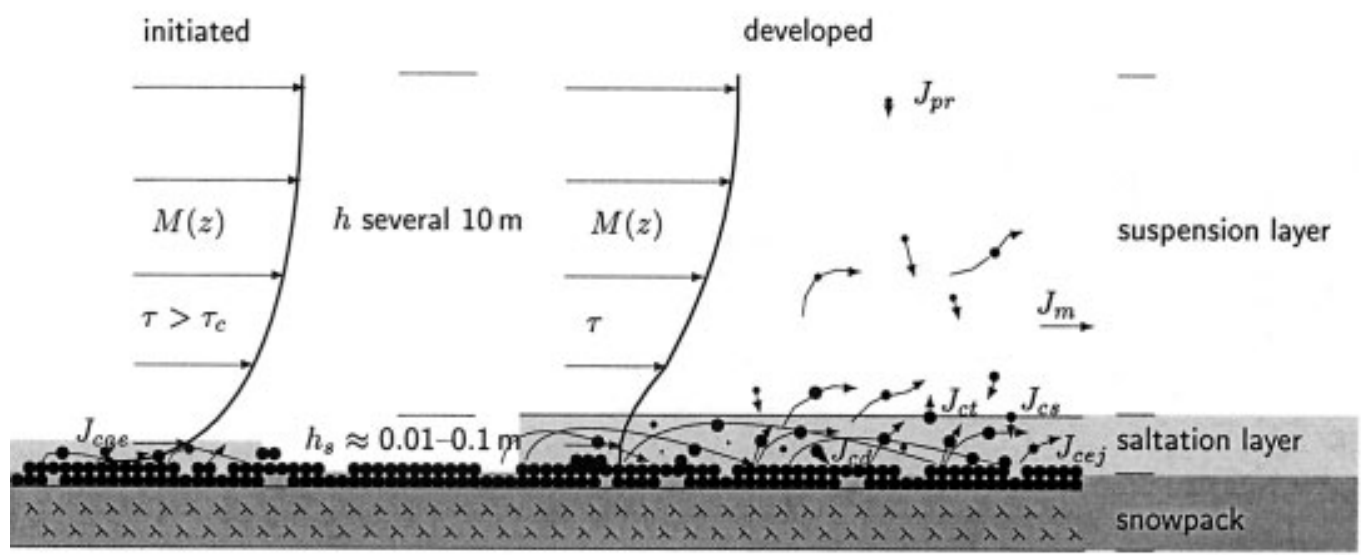

Fig. 1. Schematic diagram of the processes involved in snowdrift. $M(z)$, wind speed at a given height $z ; \tau$, shear/Reynolds stress; $\tau_{\mathrm{c}}$, critical shear stress; $J_{\text {cae, }}$, aerodynamic entrainment; $J_{\text {cej }}$, ejection rate; $J_{\mathrm{cd}}$, deposition rate; $J_{\mathrm{ct}}$, turbulent entrainment; $J_{\mathrm{cs}}$, settling rate due to gravity; $J_{\mathrm{m}}$, horizontal mass-transport rate; $J_{\mathrm{pr}}$, precipitation rate. The acceleration of grains causes a modification of the wind profile. 
considered and it is assumed that those particles are either in the saltation layer or in suspension. The complete derivation for the model is given in Gauer (1999).

\subsection{Wind-field and suspension modeling}

As outlined above, the driving force for wind-drifting snow is the airflow within the surface layer. This flow can be described using the equation of state (1), and the conservation equations for mass, momentum (3), moisture (4) and heat (5). For atmospheric flows smaller than meso- $\gamma$-scale $(\ll 12 \mathrm{~km})$, the conservation equation for mass usually reduces to the incompressibility approximation (2). Note that Einstein summation notation will be used in the following. In Equations (15), all unprimed quantities are to be understood as Reynolds averaged quantities.

$$
\begin{gathered}
\frac{p}{R_{\mathrm{a}}}=\rho_{\mathrm{a}} T_{\mathrm{v}} \\
\frac{\partial u_{j}}{\partial x_{j}}=0 \\
\frac{\partial u_{i}}{\partial t}+u_{j} \frac{\partial u_{i}}{\partial x_{j}}=-\frac{1}{\rho_{\mathrm{a}}} \frac{\partial p}{\partial x_{i}}+\nu \frac{\partial^{2} u_{i}}{\partial x_{j} \partial x_{j}} \\
+f_{\mathrm{c}} \epsilon_{i j 3} u_{j}-\frac{\partial \overline{u_{i}^{\prime} u_{j}^{\prime}}}{\partial x_{j}}-g \delta_{i 3} \\
\frac{\partial q_{\mathrm{T}}}{\partial t}+u_{j} \frac{\partial q_{\mathrm{T}}}{\partial x_{j}}=-\frac{\partial \overline{q_{\mathrm{T}}^{\prime} u_{j}^{\prime}}}{\partial x_{j}}+\frac{S_{q_{\mathrm{T}}}}{\partial \Theta}+u_{j} \frac{\partial \Theta}{\partial x_{j}}=\nu_{\Theta} \frac{\partial^{2} \Theta}{\partial x_{j} \partial x_{j}}-\frac{1}{\rho_{\mathrm{a}} C_{\mathrm{p}}} \frac{\partial I_{j}}{\partial x_{j}} \\
-\frac{L_{\mathrm{p}} E}{\rho_{\mathrm{a}} C_{\mathrm{p}}}-\frac{\partial u_{j}^{\prime} \Theta^{\prime}}{\partial x_{j}} .
\end{gathered}
$$

In Equation (4), $q_{\mathrm{T}}$ denotes the total specific humidity of air, which can be split into a vapor and a non-vapor part, using $q_{\mathrm{T}}=q+q_{\mathrm{L}}$. The heat balance (Equation (5)) is expressed in terms of the potential temperature, $\Theta=T\left(p_{0} / p\right)^{R_{\mathrm{a}} / C_{\mathrm{p}}}$. The virtual temperature, $T_{\mathrm{v}}$, is defined as the temperature at which dry air must be in order to have the same density as moist air at the temperature $T$. It is given by

$$
\begin{aligned}
& T_{\mathrm{v}}=T\left(\frac{r+0.622}{0.622}\right) \frac{1}{1+r} \text { (unsaturated) } \\
& T_{\mathrm{v}}=T\left(\frac{r_{\mathrm{sat}}+0.622}{0.622}\right) \frac{1}{1+r_{\mathrm{sat}}+r_{\mathrm{L}}} \text { (saturated) }
\end{aligned}
$$

where $r$ is the mixing ratio, and $r_{\text {sat }}$ and $r_{\mathrm{L}}$ are the saturation and solid/liquid water mixing ratios, respectively. By substituting Equation (6) into Equation (1), effects of mass concentration on the wind flow can be taken into account. For a complete derivation of these equations, the reader is referred to the literature (Pichler, 1986, Stull, 1997). In the following, it will be assumed that temperature effects, sublimation and effects due to the Coriolis term, $f_{\mathrm{c}} \epsilon_{i j 3} u_{j}$, are negligible for the present purpose of the model. It is assumed that snow grains travel with a velocity $U_{P_{i}}=u_{i}-W_{\mathrm{f}} \delta_{i 3}$, where $W_{\mathrm{f}}$ is the absolute value of the free-fall velocity of a grain. This assumption implies that all grains have the same size. On the conditions above, Equation (5) is negligible, a fixed reference temperature,
$T_{\text {ref }}$, can be used, and Equation (4) can be replaced by the balance equation for only the solid part,

$$
\frac{\partial q_{\mathrm{L}}}{\partial t}+u_{j} \frac{\partial q_{\mathrm{L}}}{\partial x_{j}}=-\frac{\partial}{\partial x_{j}}\left(\overline{q_{\mathrm{L}}^{\prime} u_{j}^{\prime}}-q_{\mathrm{L}} W_{\mathrm{f}} \delta_{j 3}\right),
$$

to describe precipitation as well as the suspension transport. The solid part of the moisture can be written as $q_{\mathrm{L}}=c \rho_{\mathrm{P}} / \rho_{\mathrm{a}}$, where $c$ is the volume fraction of snow and $\rho_{\mathrm{P}}$ is the intrinsic density of ice. On the righthand side of Equation (7), a sink/ source term for the phase change due to sublimation is neglected. The sublimation rate of an ice particle is determined by the difference between the saturation vapor pressure over ice, as a function of the particle radius, and the water-vapor pressure of the ambient air. At the present stage, the model will be used to represent the redistribution of snow during precipitation events with a relative humidity of approximately $100 \%$. In this case, it is reasonable to assume that the difference in the vapor pressures is small and hence the sublimation loss negligible. Otherwise, the sublimation rate must be parameterized (as in Liston and Sturm, 1998), or in a consistent manner the phase exchange, $-E / \rho_{\mathrm{a}}$, must be included on the righthand side of Equation (7) and an additional equation for the vapor part is needed. As phase exchange depends on the grain-size, the grain-size distribution should be considered. Also the latent-heat transfer should be taken into account, so that Equation (5) is no longer negligible. The particle temperature, which determines the saturation vapor pressure, is influenced by the absorbed solar radiation. This fact as well as Equation (5) require an approximation of the incoming solar radiation.

For turbulent closure, the well-known $e-\epsilon$ model is used (see, e.g., Rodi, 1980). This was first used in a snowdrift model by Liston and others (1993) in their two-dimensional model, and has been used to simulate boundary-layer evolution, flow changes in roughness and topography, and sea-breeze fronts (Stull, 1997). It is a one-and-a-half-order closure and is used as a compromise between accuracy and effort. Here, Reynolds stress and Reynolds flux are approximated by

$$
-\overline{u_{i}^{\prime} u_{j}^{\prime}}=\nu_{\mathrm{T}}\left(\frac{\partial u_{i}}{\partial x_{j}}+\frac{\partial u_{j}}{\partial x_{i}}\right)-\frac{2}{3} e \delta_{i j}
$$

and

$$
-\overline{u_{i}^{\prime} q_{\mathrm{L}}^{\prime}}=\frac{\nu_{\mathrm{T}}}{\sigma_{\mathrm{T}}} \frac{\partial q_{\mathrm{L}}}{\partial x_{i}},
$$

where the turbulent viscosity is parameterized by

$$
\nu_{\mathrm{T}}=c_{\mu} \frac{e^{2}}{\epsilon} .
$$

Separate balance equations are formulated for the turbulent kinetic energy, $e$, and the dissipation rate, $\epsilon$, i.e.

$$
\begin{array}{r}
\frac{\partial e}{\partial t}+u_{j} \frac{\partial e}{\partial x_{j}}=\frac{\partial}{\partial x_{j}}\left[\left(\nu+\frac{\nu_{\mathrm{T}}}{\sigma_{\mathrm{e}}}\right) \frac{\partial e}{\partial x_{j}}\right] \\
-\overline{u_{i}^{\prime} u_{j}^{\prime}} \frac{\partial u_{i}}{\partial x_{j}}-g \overline{q_{\mathrm{L}}^{\prime} u_{j}^{\prime}} \delta_{j 3}-\epsilon
\end{array}
$$

and

$$
\begin{aligned}
\frac{\partial \epsilon}{\partial t} & +u_{j} \frac{\partial \epsilon}{\partial x_{j}}=\frac{\partial}{\partial x_{j}}\left[\left(\nu+\frac{\nu_{\mathrm{T}}}{\sigma_{\epsilon}}\right) \frac{\partial \epsilon}{\partial x_{j}}\right] \\
& +c_{1 \epsilon} \frac{\epsilon}{e}\left(\overline{u_{i}^{\prime} u_{j}^{\prime}} \frac{\partial u_{i}}{\partial x_{j}}-g \overline{q_{\mathrm{L}}^{\prime} u_{j}^{\prime}} \delta_{j 3}\right)-c_{2 \epsilon} \frac{\epsilon^{2}}{e}
\end{aligned}
$$

The empirical constants are set to $c_{\mu}=0.09, c_{1 \epsilon}=1.44$, $c_{2 \epsilon}=1.92, \sigma_{\mathrm{T}}=0.9, \sigma_{\mathrm{e}}=1.0$ and $\sigma_{\epsilon}=1.3$ (Rodi, 1980).

The description of the suspension layer above is similar 
to simple mixture formulations used in the description of passive tracers and in air-pollution modeling. As in those models, momentum transfer between the different phases is assumed negligible. However, mass change due to the suspension of snow is included here. Naaim and others (1998) used a slightly modified $e-\epsilon$ for their snowdrift model to account for the effect that particles have on turbulence.

\subsection{Saltation-layer modeling}

Within the saltation layer, the assumption of a negligible momentum transfer breaks down, as the acceleration of massive grains exerts an additional force on the wind. Hence, within the saltation layer, the mass balance and the momentum balance are formulated for each of the two phases, dry air and snow. Scaling analysis (Gauer, 1999) shows that mass conservation within the saltation layer is primarily determined by the conservation of the snow mass

$$
\frac{\partial \rho_{\mathrm{P}} c}{\partial t}+\frac{\partial \rho_{\mathrm{P}} c U_{P_{i}}}{\partial x_{i}}=0
$$

and that the reduced mixture momentum equation describes the balance of the force necessary to accelerate the saltating particles and the driving forces, represented by the Reynolds/ shear stress and gravity. Therefore,

$$
\rho_{\mathrm{P}} c \frac{\mathrm{d} U_{P i}}{\mathrm{~d} t}=\rho_{\mathrm{d}} \frac{\partial \tau_{i 3}}{\partial x_{3}}-\left(\rho_{\mathrm{P}}-\rho_{\mathrm{d}}\right) c g_{i},
$$

where $\rho_{\mathrm{d}}$ is the density of dry air. In the numerical model, the following discretized volume-averaged versions of Equations (13) and (14) are used

$$
\begin{array}{r}
\frac{\Delta\left(\rho_{\mathrm{P}} c V\right)}{\Delta t}=-\sum_{k}^{(1,2,4,5)} \rho_{\mathrm{P}} c \boldsymbol{C}_{\langle k\rangle} \\
+J_{\mathrm{cs}}-J_{\mathrm{ct}}+J_{\mathrm{ce}}-J_{\mathrm{cd}}
\end{array}
$$

and

$$
\begin{aligned}
c_{\mathrm{R}} V \frac{\Delta U_{P_{\mathrm{R}}}}{t_{\mathrm{R}}} & +c_{\mathrm{E}} V \frac{\Delta U_{P_{\mathrm{E}}}}{t_{\mathrm{E}}} \\
& =\frac{\tau_{h_{\mathrm{s}}} A^{\langle 3\rangle}}{\rho_{\mathrm{P}}}-\frac{\tau_{\mathrm{a}} A^{\langle 6\rangle}}{\rho_{\mathrm{P}}}-c V g \sin \phi,
\end{aligned}
$$

where sub/superscripts $\langle 1\rangle,\langle 2\rangle,\langle 3\rangle,\langle 4\rangle,\langle 5\rangle$ and $\langle 6\rangle$ stand for the direction of the control volume in $x, y, z,-x,-y$ and $-z$, respectively, $\Delta U_{P_{\mathrm{R}}} / t_{\mathrm{R}}$ and $\Delta U_{P_{\mathrm{E}}} / t_{\mathrm{E}}$ are the approximated slope-parallel acceleration acting on a rebounding or ejected grain, respectively, during its jump, and $c_{\mathrm{R}}$ and $c_{\mathrm{E}}$ are the corresponding parts of the volume fraction of snow, $c$, within the saltation layer. Let us assume that the ratio of rebounding and ejected grains in a control volume will remain unchanged due to advection during a time-step. In this case,

$$
c_{\mathrm{E}}^{(t)}=\frac{c_{\mathrm{E}_{\text {calc }}}^{(t-1)}}{c_{\mathrm{R}_{\text {calc }}}^{(t-1)}+c_{\mathrm{E}_{\text {calc }}}^{(t-1)}} c^{(t)}
$$

and

$$
c_{\mathrm{R}}^{(t)}=\left(1-\frac{c_{\mathrm{E}_{\text {calc }}}^{(t-1)}}{c_{\mathrm{R}_{\text {calc }}}^{(t-1)}+c_{\mathrm{E}_{\text {calc }}}^{(t-1)}}\right) c^{(t)},
$$

where $c_{\mathrm{R}_{\text {calc }}}^{(t-1)}$ and $c_{\mathrm{E}_{\text {calc }}}^{(t-1)}$ are the calculated particle concentrations of rebounding and ejected particles, respectively, from the previous time-step. The advection coefficients are given by

$$
C_{\langle k\rangle}=\bar{U}_{P_{i}} A_{i}^{\langle k\rangle}, \quad k=(1,2,4,5)
$$

where $\bar{U}_{P_{i}}$ denotes the vector of the mean particle velocity and $A_{i}^{\langle k\rangle}$ are the area vectors of the sides in the direction $k$ of the control volume. The volume $V$ is approximated by $A^{\langle 6\rangle} h_{\mathrm{s}}$, where $A^{\langle 6\rangle}$ is the surface area and $h_{\mathrm{s}}$ is the saltation height. A parameterization of $\bar{U}_{P_{i}}, h_{\mathrm{S}}, \Delta U_{P_{\mathrm{R}}} / t_{\mathrm{R}}$, etc., will be defined later on.

\subsubsection{Concentration exchange between saltation and suspension layer} The settling due to gravity, $J_{\mathrm{cs}}$, and the turbulent entrainment, $J_{\text {ct }}$, determine the boundary conditions of the concentration exchange between the saltation layer and the suspension layer. Grains settle out of the suspension layer through the boundary area, $A^{\langle 3\rangle}$, at velocity $U_{P_{i}}=$ $u_{h_{\mathrm{s}_{i}}}-W_{\mathrm{f}} \delta_{i 3}$. Turbulent fluctuations will also influence the settling. On the other hand, grains in the saltation layer can be caught by turbulent eddies and lifted off, and then transported by the mean flow. For the description of the mass exchange the following statement is used:

$$
\begin{gathered}
J_{\mathrm{cs}}=\rho_{\mathrm{P}} c_{\mathrm{s}} A_{\langle 3\rangle} \\
J_{\mathrm{ct}}=\rho_{\mathrm{P}} c\left(A_{\langle 3\rangle}+\mathrm{C}_{\langle 3\rangle}\right),
\end{gathered}
$$

where $A_{\langle 3\rangle}$ is set to

$$
A_{\langle 3\rangle}=\max \left(0.5\left|C_{3}\right|, D_{3}\right)-0.5 C_{\langle 3\rangle},
$$

and $C_{\langle 3\rangle}$ is given by

$$
C_{\langle 1\rangle}=\left(u_{h_{\mathrm{s}_{i}}} n_{i}\right) n_{j} A_{j}^{\langle 3\rangle}-W_{\mathrm{f}} A_{j}^{\langle 3\rangle} \delta_{j 3}
$$

and the diffusion coefficient describing the turbulent dispersion is set to

$$
D_{\langle 3\rangle}=\sqrt{\frac{5 e}{11}} A^{\langle 3\rangle} .
$$

$n_{i}$ is the normal vector to the boundary area between the saltation layer and the suspension layer, $A_{j}^{\langle 3\rangle}$ is the area vector. $u_{h_{\mathrm{s}_{i}}}$ is the wind velocity at the saltation-layer height and $c_{\mathrm{S}}$ is the volume fraction of snow in the suspension layer above. The value $\sqrt{5 e / 11}$ is obtained by similarity theory for the neutral boundary layer and corresponds to the vertical fluctuation velocity (Stull, 1987). The statement for the mass exchange is adapted from a hybrid differencing scheme in which central differencing is used if the mesh Peclet number $(C / D)$ is $<2$, and upwind differencing, neglecting diffusion, is used if the mesh Peclet number is $>2$.

\subsubsection{Erosion and deposition}

Although Bagnold (1954), in one of the first thorough examinations of the drift processes, recognized the difference between fluid threshold and impact threshold, most models do not distinguish between aerodynamic entrainment and ejecta due to impact. Anderson and others (1991) as well as McEwan and Willets (1993) emphasized the importance of the impact process for particle entrainment, and it is observed that threshold wind speeds are significantly reduced if there are already snow grains in the air.

The mass exchange between the snowpack and the saltation layer is determined by erosion and deposition of snow grains. As mentioned above, two different mechanisms are important for erosion: aerodynamic entrainment and particle impact. At present, little is known about the exact nature of either mechanism in the case of snow. In the absence of better knowledge on aerodynamic entrainment, the statement proposed by Anderson and Haff (1991) is adopted, i.e. a linear relation between the number of entrained grains per 
unit area and unit time, $N_{\mathrm{ae}}$, and the excess shear stress is used. Thus,

$$
J_{\text {cae }}=\zeta \max \left(\tau_{\mathrm{a}}-\tau_{\mathrm{c}}, 0\right) A^{\langle 6\rangle} \rho_{\mathrm{P}} V_{\mathrm{P}},
$$

where $\tau_{\mathrm{a}}$ is the so-called airborne shear stress and is assumed to be equal to the shear stress of the airflow at the bed, $\tau_{\mathrm{c}}$ is the critical fluid shear stress for entrainment and $\zeta$ is an empirical constant. As no value is known for the case of snow, $\zeta=10^{5}$ grains $\mathrm{N}^{-1} \mathrm{~s}^{-1}$ is used, which is the value used by Anderson and Haff for sand. Actually, the choice of $\zeta$ is not that important, as fluid entrainment essentially acts during the initial development of wind transport. Once there are some particles in transport, they act as seeding agents for further dislodgements. The impacts between these particles and the surface eject more particles, leading to a cascade as mentioned above. This cascade drives the transition from an aerodynamically controlled to an impact-controlled system. More important is the choice of $\tau_{\mathrm{c}}$, which determines the onset of drift, at least during periods without additional precipitation. $\tau_{\mathrm{c}}$ is highly dependent on the snowpack properties and meteorological conditions such as particle size and shape, bonding, temperature and humidity. Schmidt (1980) tried to estimate $\tau_{c}$ for wind conditions over a flat snow surface. According to him, values for $\tau_{\mathrm{c}}$ range from 0.04 to $9000 \mathrm{~Pa}$. In comparison, typical values for the wind shear stress/ Reynolds stress, $\tau_{\mathrm{a}}$, during snowdrift vary from 0.06 to $1 \mathrm{~Pa}$, indicating that aerodynamical entrainment is only possible within a small range. The lower end of the estimation above is in agreement with observations based on the onset of drift (see, e.g., Castelle, 1995; Li and Pomeroy, 1997). Little is known about the influence of snowpack properties and meteorological conditions on $\tau_{\mathrm{c}}$. Li and Pomeroy (1997) show a relation between air temperature and the mean threshold wind speed. An attempt to relate the threshold to snowpack properties, such as particle size, sphericity and dendricity, can be found in Guyomarc'h and Mérindol (1998).

The erosion due to particle impacts is determined by the number of particle impacts per unit time on the snow surface and the number of ejected particles per impact. The impact rate is given by

$$
N_{\mathrm{I}}=\frac{c V}{V_{\mathrm{P}} t_{\mathrm{J}}},
$$

where $V_{\mathrm{P}}$ is the particle volume and $t_{\mathrm{J}}$ is the average duration of a particle jump. To estimate the number of particles ejected per impact, $N_{\mathrm{EpI}}$, it is reasonable to assume that this number is a function of the difference of the kinetic energy of a particle before the impact, $E_{\mathrm{I}}$, and after it, $E_{\mathrm{R}}$, of the total kinetic energy of the ejected particles, $N_{\mathrm{EpI}} E_{\mathrm{E}}$, of the energy dissipated into the bed during the impact, $E_{\mathrm{D}}$, and, if cohesion is included, of the total energy of the bonds, $N_{\mathrm{EpI}} E_{\mathrm{B}}$, which had to be broken. From the energy balance, we obtain

$$
N_{\mathrm{EpI}}=\frac{E_{\mathrm{I}}-E_{\mathrm{R}}-E_{\mathrm{D}}}{E_{\mathrm{B}}+E_{\mathrm{E}}} .
$$

All these energies can be expected to depend on the mechanical properties of the snowpack, but the exact relationship is as yet unknown. To estimate a value for $N_{\mathrm{EpI}}$, some assumptions are made. The assessment for $E_{\mathrm{D}}$ was based on the numerical simulations of Anderson and Haff (1991) who found that, in the case of sand $\left(E_{\mathrm{B}}=0\right)$, the mean number of ejecta increases approximately linearly with the impact speed, where the ejection rate $N_{\mathrm{EpI}} \approx 1.5 \mathrm{~m}^{-1} \mathrm{~s}\left\|U_{\mathrm{I}}\right\|$. For the assessment of $E_{\mathrm{I}}, E_{\mathrm{R}}$ and $E_{\mathrm{E}}$ see Table 1. Figure 2 shows an approximation of the
Table 1. Typical values of the quantities characterizing the particle-bed impact
$\varsigma_{\mathrm{m}}=\frac{\left\|U_{\mathrm{I}}\right\|}{\left\|u_{h_{\mathrm{s}}}\right\|} \approx 0.6-0.7$
$\alpha_{\mathrm{I}} \approx 10-20^{\circ}$
$\varsigma_{\mathrm{R}}=\frac{\left\|U_{\mathrm{R}}\right\|}{\left\|U_{\mathrm{I}}\right\|} \approx 0.5-0.6$
$\alpha_{\mathrm{R}} \approx 35-45^{\circ}$
$\varsigma_{\mathrm{E}}=\frac{\left\|U_{\mathrm{E}}\right\|}{\left\|U_{\mathrm{I}}\right\|} \approx 0.1$
$\alpha_{\mathrm{E}} \approx 50-70^{\circ}$

ejection rate with $E_{\mathrm{B}}$ as parameter. The range of $E_{\mathrm{B}}$ from $10^{-10}$ to $10^{-8} \mathrm{~J}$ seems to be reasonable regarding different snow types (Schmidt, 1980; Gubler, 1982). Using Equations (26) and (27), the ejection rate can be expressed as

$$
J_{\text {cej }}=\left\lfloor N_{\mathrm{EpI}}\right\rfloor \rho_{\mathrm{P}} V\left(\frac{c_{\mathrm{R}}}{t_{\mathrm{R}}}+\frac{c_{\mathrm{E}}}{t_{\mathrm{E}}}\right) .
$$

Here and in Equations (29) and (30), there is a distinction between rebounding particles and those particles which were just ejected because their respective impact speed $U_{\mathrm{I}}$ and jump time $t_{\mathrm{J}}$ are significantly different. Both kinds are marked by subscript ()$_{\mathrm{R}}$ and ()$_{\mathrm{E}}$, respectively.

Snow grains in saltation tend to rebound at the surface. On the other hand, if a snow grain does not rebound it will be deposited at the surface. Hence, if $P_{\mathrm{R}}$ is the probability that a snow grain will rebound on impact, $1-P_{\mathrm{R}}$ is the probability that it will be deposited. Thus, the deposition rate can be described by

$$
J_{\text {cd }}=\rho_{\mathrm{P}} V\left[\left(1-P_{\mathrm{R}}\right) \frac{c_{\mathrm{R}}}{t_{\mathrm{R}}}+\left(1-P_{\mathrm{R}}\right) \frac{c_{\mathrm{E}}}{t_{\mathrm{E}}}\right] .
$$

Physical simulations (Kosugi and others, 1995; Rice and others, 1995, 1996) show that the probability of a particle rebounding is approximately $0.6-0.9$ for the investigated impact speeds. In the absence of better data, the relation

$$
P_{\mathrm{R}}=0.95\left[1-\exp \left(-\xi\left\|U_{\mathrm{I}}\right\|\right)\right]
$$

is used, which Anderson and Haff (1991) proposed for sand. Assuming that the rebound probability for a snow grain at the surface of a snowpack is smaller than for a sand particle on a bed of sand, the coefficient $\xi$ is set to $1.5 \mathrm{~m}^{-1} \mathrm{~s}$ instead of the original value, $2 \mathrm{~m}^{-1} \mathrm{~s}$. Actually, the rebound probability is expected to depend on the snowpack properties, but little is known about the relationship as yet.

\subsubsection{Modification of the wind field}

Bagnold (1954) was the first to note the feedback between

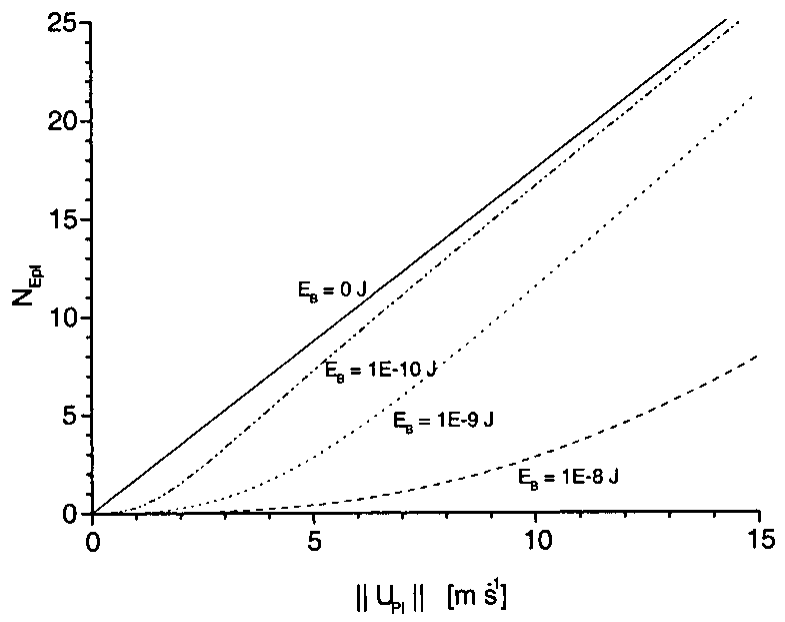

Fig. 2. Approximation of the ejection rate for snow particles due to particle impact as function of the impact speed for different values of the bonding energy, $E_{\mathrm{B}}$. 
particle movement and the driving wind. Thereafter, it became common to parameterize the interaction between the particles in the saltation layer (extraction of momentum) and the wind above, using an increased roughness length, $z_{0}$, in the equation for the logarithmic wind profile

$$
M(z)=\frac{u_{*}}{\kappa} \ln \left(\frac{z}{z_{0}}\right) .
$$

Owen (1964) assumed that the saltation-layer height scales as $u_{*}^{2} /(2 g)$ and that the roughness length can be given by

$$
z_{0}=k \frac{u_{*}^{2}}{2 g} .
$$

However, there are two weak points. First, it is unreasonable to assume that the roughness length depends only on the saltation-layer height and that there is no dependency on the number of particles within the saltation layer. This oversimplification might explain why there is a large difference in the reported values for the constant $k$. Owen proposed $k=0.02$, whereas Rasmussen and others (1985) reported values of 0.14 and 0.18, and Pomeroy and Gray (1990) set $k$ to 0.1203. Second, Equation (31) cannot represent the rapid decrease in the wind speed just above the top of the saltation layer $\left(h_{\mathrm{s}} \approx\right.$ $1-2 \mathrm{~cm})$, an effect which can be observed, for example, in Bagnold's classical wind-velocity plot (Bagnold, 1954, fig. 17).

The primary effect that the particles have on the airflow is to provide a spatially distributed momentum sink, with sink strength $\mathrm{d} \tau_{\mathrm{a}}(z) / \mathrm{d} z \cong-\mathrm{d} \tau_{\mathrm{g}}(z) / \mathrm{d} z$ per unit volume of fluid. $\tau_{\mathrm{a}}(z)$ is the flux of fluid momentum across the level $z$, and $\tau_{\mathrm{g}}(z)$ represents the net flux of slope-parallel grain momentum across that level. $\mathrm{d} \tau_{\mathrm{g}}(z) / \mathrm{d} z$ corresponds to the interaction (drag) forces on the wind, due to the slope-parallel acceleration of the grains by the air. This acceleration mainly takes place within the saltation layer. The total shear stress is given by

$$
\tau_{h_{\mathrm{s}}}=\tau_{\mathrm{a}}(z)+\tau_{\mathrm{g}}(z),
$$

where $\tau_{h_{\mathrm{s}}}$ is the stress at the top and above the saltation layer. Vegetation canopies have a similar effect on flow. In boundary-layer meteorology, it is customary to describe the effect of vegetation on the flow above by a generalized logarithmic law (Thom, 1971; Jackson, 1981; Wieringa, 1993). In such a case,

$$
M(z)=\frac{u_{*}}{\kappa} \ln \left(\frac{z-d}{z_{0}}\right),
$$

where $d$ is the displacement height and $z_{0}$ is the roughness length. According to Thom (1971) and Jackson (1981), $z_{0}$ expresses the magnitude of forces acting on the surface, whereas $d$ is related to the distribution in $z$ of these forces. Hence, for a known distribution of the interaction (drag) forces within the saltation layer, $F_{\mathrm{DW}}(z)$, the displacement height can be calculated according to the statement of Shaw and Pereira (1982):

$$
d=\left(\frac{\tau_{h_{\mathrm{s}}}-\tau_{\mathrm{a}}}{\tau_{h_{\mathrm{s}}}}\right) \frac{\int_{0}^{h_{\mathrm{s}}} z F_{\mathrm{DW}}(z) \mathrm{d} z}{\int_{0}^{h_{\mathrm{s}}} F_{\mathrm{DW}}(z) \mathrm{d} z},
$$

where $\tau_{h_{\mathrm{s}}}$ and $\tau_{\mathrm{a}}$ are the airborne stresses at the top of the saltation layer and at the surface of the snowpack, respectively. Assuming that the particles do not influence each other, the interaction force can be written as

$$
F_{\mathrm{DW}}(z)=\sum_{k=0}^{N(z)} \rho_{\mathrm{a}} C_{\mathrm{D}}(z) \frac{\pi d_{\mathrm{P}}^{2}}{8}\left|U_{\varrho_{1_{k}}}(z)\right| \max \left(0,-U_{\varrho_{1_{k}}}(z)\right),
$$

where $N(z)$ is the number of particles in a height $z$ with a slope parallel to the relative velocity $U_{\varrho_{1}}(z)$. $C_{\mathrm{D}}$ is the drag coefficient and $d_{\mathrm{P}}$ is the grain diameter. In Equation (37), only the acceleration of the grains due to the wind is represented. The reverse transfer of momentum due to descending grains from faster flow levels causes an enhancement of the air velocity close to the surface. This departure from the logarithmic wind profile within the saltation layer is observed, for example, by Bagnold (1954) and is also reported by Maeno and others (1979). For the parameterization, this departure is taken into account, as discussed in the following subsection.

For the description of the roughness length, the following statement is used:

$$
z_{0}=\max \left[\lambda\left(\frac{\tau_{h_{\mathrm{s}}}-\tau_{\mathrm{a}}}{\tau_{h_{\mathrm{s}}}}\right)\left(h_{\mathrm{s}}-d\right), z_{0 \mathrm{~s}}\right],
$$

where $z_{0 \mathrm{~s}}$ is the aerodynamic roughness length for a snow cover without saltation, typically in the range $10^{-4}$ to $10^{-3} \mathrm{~m}$ (Stull, 1997, p. 380), here set to $3 \times 10^{-4} \mathrm{~m}$, and, in the absence of data for snow transport, $\lambda$ is assumed to be 0.1 , a value used for vegetation. Equation (34) is used as a boundary condition for the wind speed, $\left\|u_{h_{\mathrm{s}}}\right\|$, at the interface between the saltation and suspension layers (see section 2.4), assuming that, at least in the lowest part of the suspension layer, a logarithmic profile exists.

\subsection{Parameterization}

To close the system of equations for the saltation model, $h_{\mathrm{s}}$, $d, \Delta U_{\mathrm{P}_{\mathrm{R}}} / t_{\mathrm{R}}, \Delta U_{\mathrm{P}_{\mathrm{E}}} / t_{\mathrm{E}}$, etc., must be determined.

The transport within the saltation layer is regulated by the motion of saltating grains, bouncing off the snow surface and following ballistic trajectories. It is widely accepted that the saltation trajectories are governed by the following relation:

$$
\begin{array}{r}
m_{\mathrm{P}} \frac{\mathrm{d} U_{P i}}{\mathrm{~d} t}=F_{G i}+F_{D i}+F_{L i}+F_{M i} \\
\text { I } \quad \text { II } \quad \text { III } \quad \text { IV } \\
+F_{A i}+F_{P i}+F_{E i}+F_{B i} \\
\text { V } \quad \text { VI } \quad \text { VII }
\end{array}
$$

where the terms on the righthand side denote the gravitational force (I), the drag force (II), the lift force (III), Magnus force (IV), added mass force (V), pressure-gradient term (VI), electrostatic force (VII) and the Basset history term (VIII) (for reference see, e.g., Clift and others, 1978, ch.11; Schmidt and others, 1998). With the aid of an appropriate scale analysis (Gauer, 1999), it can be shown that, in a first approximation, Equation (38) reduces to a balance of inertial, drag and gravity forces, such that:

$$
\frac{\mathrm{d} U_{P i}}{\mathrm{~d} t}=-\frac{3}{4} \frac{\rho_{\mathrm{a}}}{\rho_{\mathrm{P}} d_{\mathrm{P}}} C_{\mathrm{D}}\left\|U_{\varrho}\right\| U_{\varrho i}-g_{i},
$$

where $U_{\varrho_{i}}$ is the relative velocity between the particle and the airflow $\left(U_{\varrho_{i}}=U_{P i}-u_{i}\right)$. These equations form a system of differential equations which can be solved for given initial conditions, $U_{P 0 i}$, and a known wind field, $u_{i}$. They build the basis for parameterization of the saltation layer.

Physical simulations with sand and snow (Kosugi and others, 1995; Rice and others, 1995, 1996; Nishimura and others, 1998), as well as numerical simulations (Werner and Haff, 1988; Anderson and Haff, 1991) of the particle-bed impact, have been carried out. All these studies confirm that impacting particles behave in similar ways, in that they have a certain probability to rebound, and that the mean impact, launch angles, and ratio of impact to rebound 
velocity vary only over a small range. Ejected particles also behave in a specific manner. Typical values of the quantities describing the particle-bed impact are shown in Table 1 (for notation see Fig. 3).

$\varsigma_{\mathrm{R}}, \varsigma_{\mathrm{E}}, \alpha_{\mathrm{R}}$, and $\alpha_{\mathrm{R}}$ describe the particle--snowpack interaction on impact (e.g. $\varsigma_{R}$ characterizes the energy loss of a rebounding grain on impact). All these parameters are expected to be affected by the mechanical properties of the snowpack, but little is known about the relationship as yet. For our parameterization, the following values are chosen: $\varsigma_{\mathrm{R}}=0.5, \varsigma_{\mathrm{E}}=0.1, \alpha_{\mathrm{R}}=40^{\circ}$ and $\alpha_{\mathrm{E}}=65^{\circ}$. Furthermore, within the saltation layer the similarity assumptions are made, i.e. the airflow velocity, $u_{i}$, and the concentration, $c$, maintain approximately similar profiles in the $z$ direction (perpendicular to the surface) as they change in time or in the $x$ and $y$ directions. In particular, it is assumed that

$$
\begin{aligned}
u_{i}(x, y, z, t) & =\xi_{u} u_{h_{s_{i}}}(x, y, t) \\
c(x, y, z, t) & =\xi_{c} c_{h_{\mathrm{s}}}(x, y, t),
\end{aligned}
$$

where $\xi_{u}=\left[1+\varsigma\left(1-z / h_{\mathrm{s}}\right)\right]^{-2}$ with $\varsigma=0.35$, and $\xi_{\mathrm{c}}=1$ is assumed. Based on the assumptions above and on Equation (39) as well as on values given in Table 1, it is possible to calculate the trajectory of a single grain. To be consistent, the determination of the wind field within the saltation and the particle trajectories should be carried out simultaneously. The use of the profile function (Equation (40)) is a simplification, where it is assumed that the momentum extraction and the modification of $u_{i}$ due to the particles is similar to the case of vegetation. Figure 4 shows an example of such a calculation. Here, the normalized horizontal velocity of a rebounding particle is presented as a function of the normalized height for the ascending as well as the descending

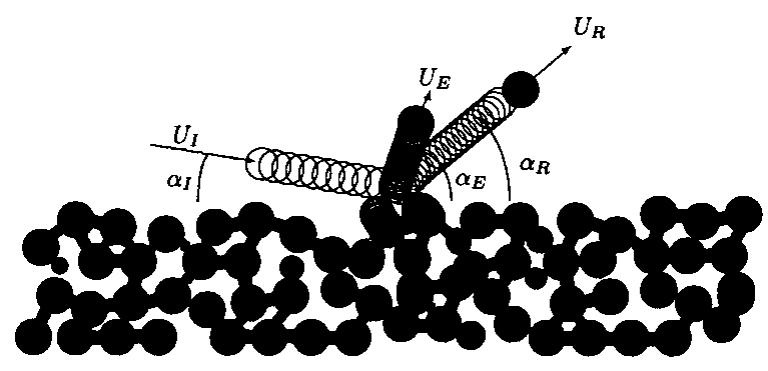

Fig. 3. Sketch of grain impact: a particle with velocity $U_{\mathrm{I}}$ impacts at angle $\alpha_{\mathrm{I}}$ on the snowpack and rebounds with velocity $U_{\mathrm{R}}$ and at angle $\alpha_{\mathrm{R}}$. In addition, a particle may be ejected with velocity $U_{\mathrm{E}}$ at angle $\alpha_{\mathrm{E}}$.

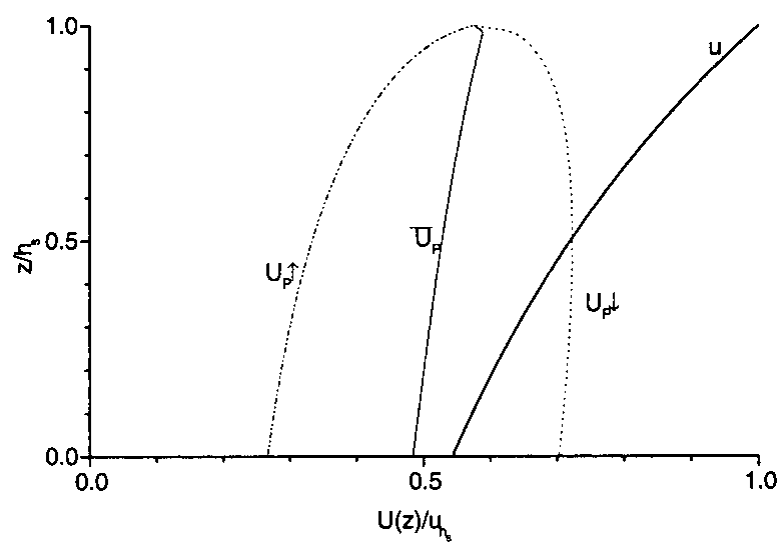

Fig. 4. Normalized slope horizontal particle velocities as a function of the normalized height for a rebounding grain, $\alpha_{\mathrm{R}}=40^{\circ}$, and $u_{h_{\mathrm{s}}}=4 \mathrm{~ms}^{-1}$; ascending $U_{\mathrm{P}} \uparrow$, descending $U_{\mathrm{P}} \downarrow$, mean $\bar{U}_{\mathrm{P}}$ and the wind speed, $u$. branch of the trajectory. The mean horizontal velocity, $\bar{U}_{\mathrm{P}}=\left(U_{\mathrm{P}} \uparrow+U_{\mathrm{P}} \downarrow\right) / 2$, and the assumed wind profile within the saltation layer are also shown. The mean particle velocity $\bar{U}_{\mathrm{P}}$ is approximately $0.5-0.6 u_{h_{\mathrm{s}}}$. Calculations with varying $u_{h_{\mathrm{s}}}$ show similar results. In the saltation model, $\bar{U}_{\mathrm{P}}$ is set to $0.58 u_{h_{\mathrm{s}}}$. The other missing parameters of the particle trajectories (e.g. $h_{\mathrm{S}}, d, \Delta U_{\mathrm{P}_{\mathrm{R}}} / t_{\mathrm{R}}$, etc.,) can also be determined in this way. Figure 5 presents those parameters as functions of $u_{h_{\mathrm{s}}}$ for a rebounding grain. Similar calculations were used to determine the corresponding quantities for ejected grains.

\subsection{Implementation}

The model is implemented in the commercial flow solver CFX4.1 from AEA Technology, England (AEA Technology, 1995). This program is based on the finite-volume technique
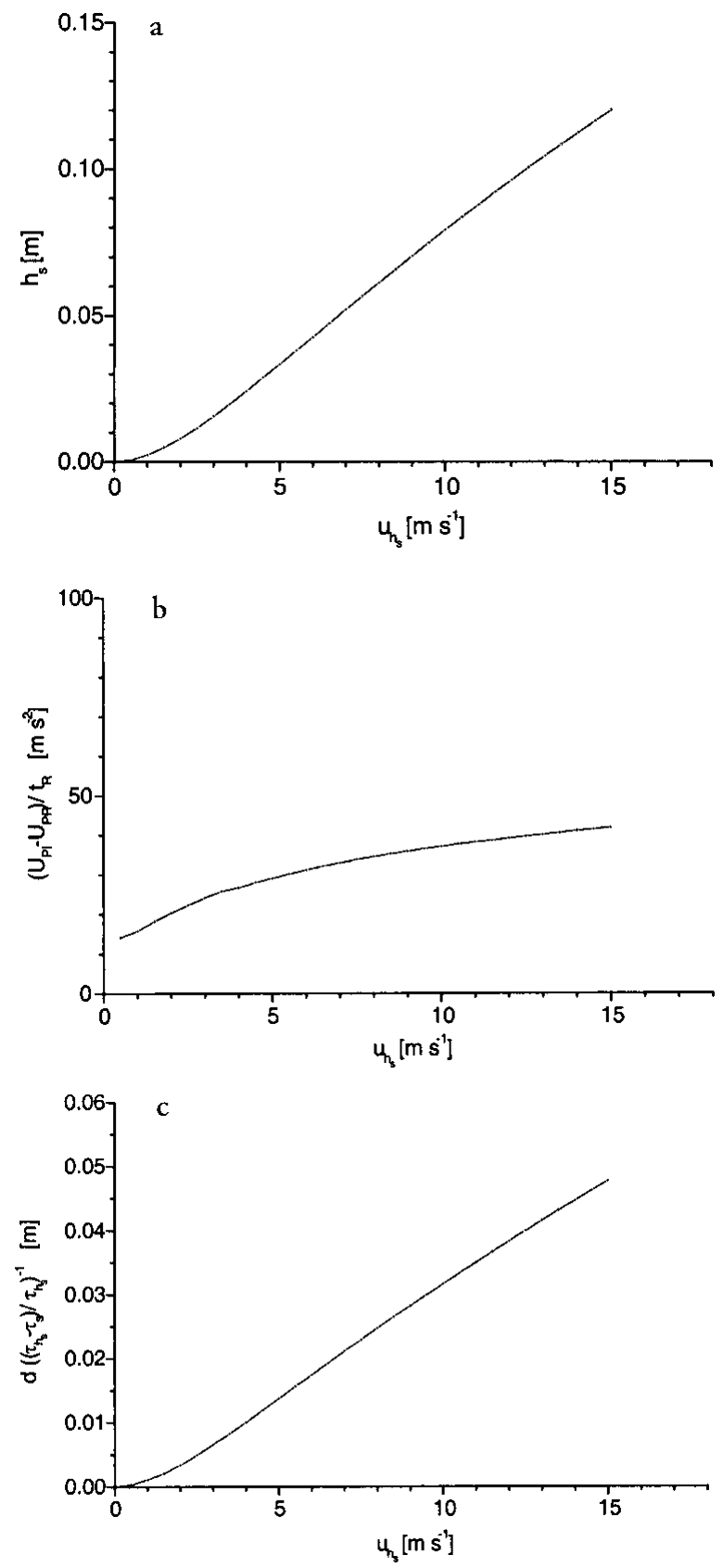

Fig. 5. Trajectory parameters as functions of the wind speed at the top of the trajectory, $u_{h_{\mathrm{s}}}$, for rebounding grains $\left(\left\|U_{\mathrm{P}_{\mathrm{R}}}\right\|=0.35\right.$ $\left.u_{h_{\mathrm{s}}}, \alpha_{\mathrm{R}}=40^{\circ}\right)$. (a) Hop/saltation layer height, $h_{\mathrm{s}}$, as a function of $u_{h_{\mathrm{s}}}$. (b) Horizontal acceleration, $\left(U_{\mathrm{P}_{\mathrm{I}}}-U_{\mathrm{P}_{\mathrm{R}}}\right) / t_{\mathrm{R}}$, as a function of $u_{h_{\mathrm{s}}}$. (c) $d\left[\left(\tau_{h_{\mathrm{s}}}-\tau_{\mathrm{a}}\right) / \tau_{h_{\mathrm{s}}}\right]^{-1}$ as a function of $u_{h_{\mathrm{s}}}$. 
and uses a body-fitted grid which can be modified during the calculation. Thus the modification of the topography due to deposition and erosion of snow can be modeled. Socalled Fortran user routines provide the programming interface for problem-specific modifications of the code and have proved flexible enough to accommodate all the extra computations for the simulation of blowing and drifting snow. Hence, the program serves as a framework, providing the solver for the wind field and for the suspension mode, whereas the calculations of the saltation mode were embedded in Fortran routines. Although the wind field, suspension and saltation form a mutually coupled system, here a certain decoupling was desired. The wind field and the suspension mode are solved together and provide the boundary condition for the saltation-layer calculation, which is carried out between two time-steps. On the other hand, the boundary conditions for the next time-step were obtained from this calculation. In order to evaluate the snowpack, the grid is adjusted to the new-snow depth at regular time intervals. For that purpose, at every time-step $\Delta \mathrm{HS}_{i}$ is calculated according to

$$
\Delta \mathrm{HS}_{i}=\max \left(\frac{J_{\mathrm{cd}}-J_{\text {cej }}-J_{\text {cae }}}{\rho_{\mathrm{P}} c_{\lambda}\left\|A^{\langle 6\rangle}\right\|} \Delta t,-\Delta \mathrm{HS}_{\mathrm{e}}\right),
$$

where $\Delta \mathrm{HS}_{\mathrm{e}}$ is the remaining erodible snow depth and $c_{\lambda}$ is the volume fraction of snow in the snow pack. After a certain number of time-steps, $n$, the grid is adjusted to the newsnow depth:

$$
\mathrm{HS}=\mathrm{HS}_{\mathrm{old}}+\sum_{i=1}^{n} \Delta \mathrm{HS}_{i}
$$

\section{FIELD MEASUREMENTS AND SIMULATION RESULTS}

To test the model, two methods were pursued. Firstly, the model was compared with experimental results described in the literature. Secondly, it was tested against data from the Gaudergrat experimental site in the Swiss Alps.

Kobayashi's (1972) are one example of measurements reported in the literature. Figure 6 shows a comparison between his field experiments and drift simulations. The mass flux, $Q$, is plotted against the wind speed at $1 \mathrm{~m}$. Kobayashi noted that due to the scattering in the drift rate, especially at low wind speeds, no distinct threshold wind speed for the occurrence of snowdrift was found, but it was in the range $4-6 \mathrm{~ms}^{-1}$. For the simulation, $\tau_{\mathrm{c}}$ was set to

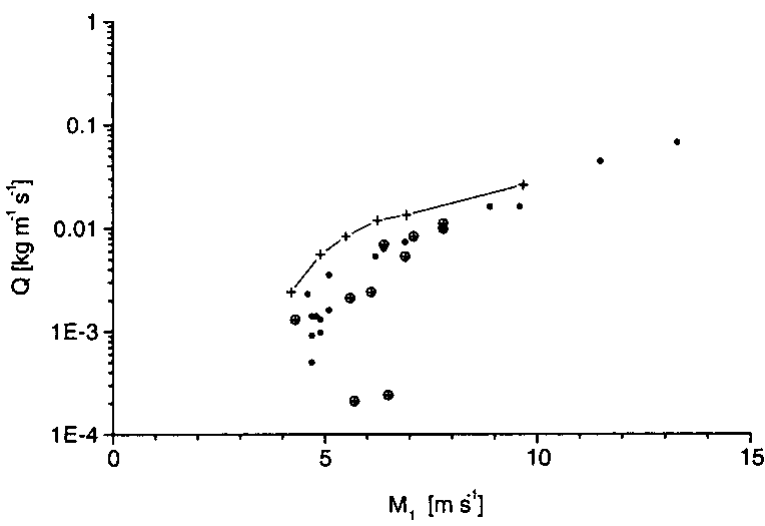

Fig. 6. Snowdrift rate as a function of the mean wind speed, $M(z=1 \mathrm{~m})$. Comparison between simulation (-+-) and measurements done by Kobayashi (1972): $\oplus$ without snowfall; - with snowfall.
$0.05 \mathrm{~Pa}$, and $E_{\mathrm{B}}$ was assumed to be $10^{-9} \mathrm{~J}$. Taking into account the uncertainties in the snowpack properties, the simulation and the measured data are in good agreement.

A logarithmic plot of the simulated steady mass flux vs $M_{0.25}$ is given in Figure 7. At low reference velocities, a rapid increase in the mass flux can be observed. Then the rate of increase diminishes with increasing $M_{0.25}$, but is still non-linear. The power decreases from approximately 4 to 2 with increasing wind speed. This decrease indicates that with increasing wind speed a saturation of transport occurs. The power range agrees quite well with those of empirical formulations given in the literature (Kobayashi, 1972; Takeuchi, 1980; Schmidt, 1982, 1986; Nishimura and others, 1998). The fit in Figure 7 corresponds to a power of approximately 3 , an oft-found value in empirical formulations. A separate comparison between measured and simulated drift rates in saltation shows that the model reproduces these rates quite well (Gauer, 1999).

In the next step, the model was applied to the Gaudergrat experimental site for a full-scale simulation of an Alpine crest. Gaudergrat ridge, $2 \mathrm{~km}$ north of Weissfluhjoch/Davos, has a rather sharp crest - the slope angles range from $28^{\circ}$ to $38^{\circ}$ - and might be regarded as prototypical of Swiss Alpine topography. The prevailing wind direction during strong precipitation periods is more or less northwest and thus perpendicular to the crest line. Up to now, field measurements of drifting snow in complex terrain are rather scarce, and, although the wind as driving force is of major importance, no example is known where the wind field and the snow distribution have been simultaneously measured. In winter 1996/97, the ridge was equipped with five wind masts in the surrounding area (M78, M76, M75, M74/73 and M72) to obtain a good impression of the wind field around the crest during interesting snowdrift periods. In addition, meteorological and snowpack parameters were measured on both sides of the ridge (M77 and M74/73). Figure 8 shows the locations of the installed masts and the slope angles at the ridge. A complete description of the experimental site and the measurements can be found in Gauer (1999).

For comparison with the simulations, the spatial snow redistribution was measured by soundings of the snow depth before and after a drift episode along five equidistant lines across the crest, roughly $8.5 \mathrm{~m}$ apart and $>200 \mathrm{~m}$ long. The soundings were taken at $4 \mathrm{~m}$ intervals along the lines; in the neighborhood of the crest this distance was reduced. Thus, every field campaign resulted in around 350 data points. All measurement points were marked by thin bamboo stakes during the first campaign, so later measurements

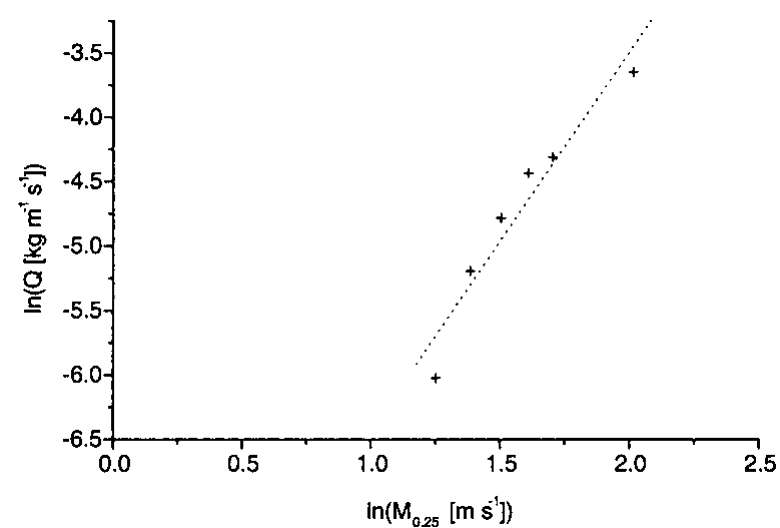

Fig. 7. Logarithmic plot of the simulated steady-state mass flux against the logarithmic $M_{0.25}$ showing the non-linear behavior. The dotted line represents the fit $\log (Q) \propto 3.1 \log \left(M_{0.25}\right)$. 
could be taken at the same points (with an estimated horizontal deviation of $<0.1 \mathrm{~m}$ ). In this manner, uncertainties in the depth measurements due to the small-scale topography were minimized. The settling of the snowpack, different for south and north aspects, between two successive soundings was taken into consideration. For this purpose, small pits were dug at several points of both slope sides, and the snow density was measured, and all new-snow depths are recalculated for the average new-snow density $\left(110 \mathrm{~kg} \mathrm{~m}^{-3}\right)$. For the comparison with the simulation these new-snow depths are normalized with $\mathrm{HN}_{\text {ref, where }} \mathrm{HN}_{\text {ref }}$ is the measured newsnow depth at the nearby Swiss Federal Institute for Snow and Avalanche Research study plot Weissfluhjoch (VF) for the corresponding periods. Correspondingly, in the simulation, $\mathrm{HN}_{\text {ref }}$ is the simulated new-snow depth unaffected by the wind. During winter 1996/97, six strong precipitation periods with snowdrift were investigated.

For the full-scale simulation of the Gaudergrat site, a horizontal area of $1000 \times 600 \mathrm{~m}^{-2}$ was chosen around the crest line (see Fig. 8). The grid consists of $120 \times 37 \times 25$ cells for the flow domain and $120 \times 37$ cells each for the saltation layer and for the snowpack. The grid spacing $\Delta x$ ranges from $15 \mathrm{~m}$ at the inflow and the outflow to approximately $2.5 \mathrm{~m}$ close to the crest line, and $\Delta y$ ranges from $20 \mathrm{~m}$ at the sides to approximately $8 \mathrm{~m}$ in the middle. In the flow domain, the spacing in the $z$ direction varies between approximately $2 \mathrm{~m}$ at the bottom and $35 \mathrm{~m}$ at the top. The time-step was set to $0.25 \mathrm{~s}$.

The upwind boundary conditions were derived from wind measurements at mast M78, and the precipitation rate was determined by

$$
p_{\mathrm{r}}(t)=1.8 \times 10^{-6} \operatorname{min~s}^{-1} \mathrm{~kg}^{-1} \mathrm{~m}^{3} \mathrm{RS}(t),
$$

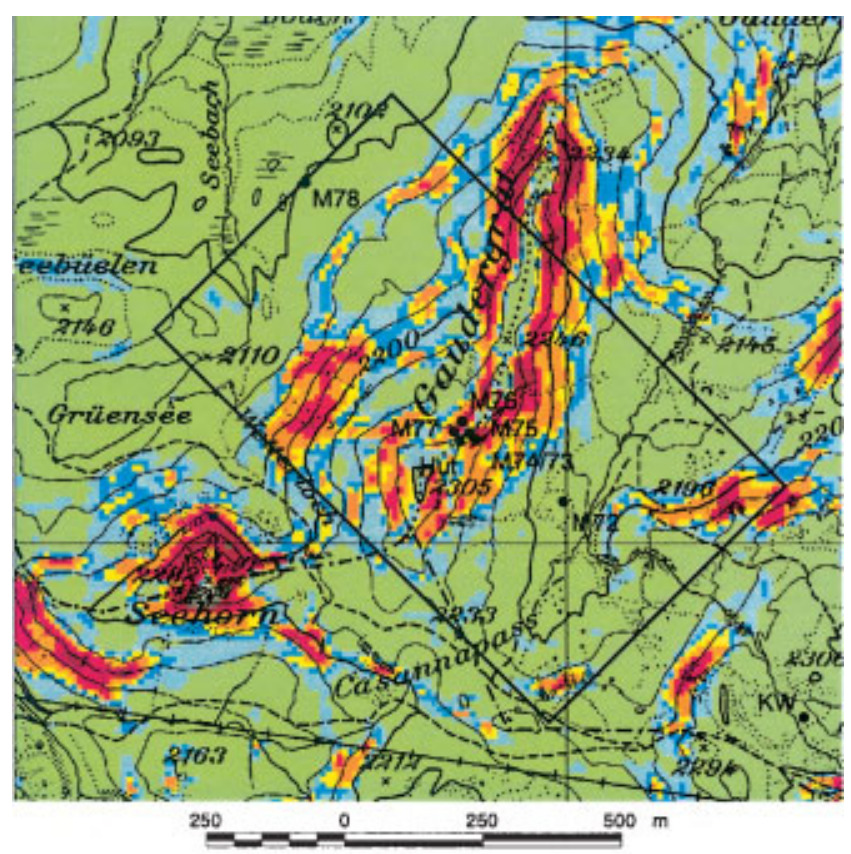

slope angle in degree:

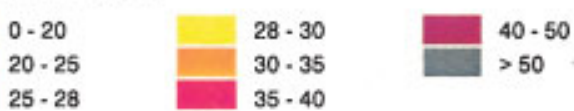

Fig. 8. Slope-angle map of the Gaudergrat experimental site showing locations of the masts $M X X$ and the hut that housed the transmitting equipment. The box marks the area of the numerical simulations. (Topographic data DHM25: (C) Swiss Federal Office of Topography.) where $\mathrm{RS}(t)$ is the measured 10 min precipitation sum at VF. All given boundary conditions were allowed to vary with the time. The initial snow depth was set to $0.2 \mathrm{~m}$ of erodible snow. During the simulation, the evolution of the snowpack was followed so that it was possible to decide if new snow was deposited or old snow eroded. For the simulation, the critical shear stress of the old snowpack was set to $\tau_{\mathrm{c}}=0.5 \mathrm{~Pa}$ and $E_{\mathrm{B}}=10^{-8} \mathrm{~J}$, whereas for deposited new snow, values of $\tau_{\mathrm{c}}=$ $0.05 \mathrm{~Pa}$ and $E_{\mathrm{B}}=10^{-9} \mathrm{~J}$ were chosen. These estimations of the critical shear stress are based on observations in the field during drift episodes. A description of these observations and a complete description of the grid and the boundary settings is given in Gauer (1999).

As an example of the wind-field measurements, Figure 9 depicts a temporal plot of the wind speed, $M$, and the direction, $d d$, approximately $2 \mathrm{~m}$ above the snowpack, for drift period 19-21 March at M76 and M73/74. The results of the corresponding numerical simulations are also shown. Generally, the simulations agree quite well with the measurements. A conspicuous feature is the turn in the wind direction from northwest on the windward side to more or less northeast to south on the leeward side of the crest. This phenomenon might be caused by a channeling effect of the topography (Fig. 8) and is reproduced also by the simulation (see also Fig. 13, shown later). While the simulated wind speeds tend to be somewhat too high windward of the crest, they are in good agreement in the lee. The scattering in the measured wind direction at mast M73/74 indicates the highly turbulent character of the wind field just leeward of the crest. It is still impractical to fully resolve this turbulent flow in the natural environment. Nevertheless, for of most of the time the simu-
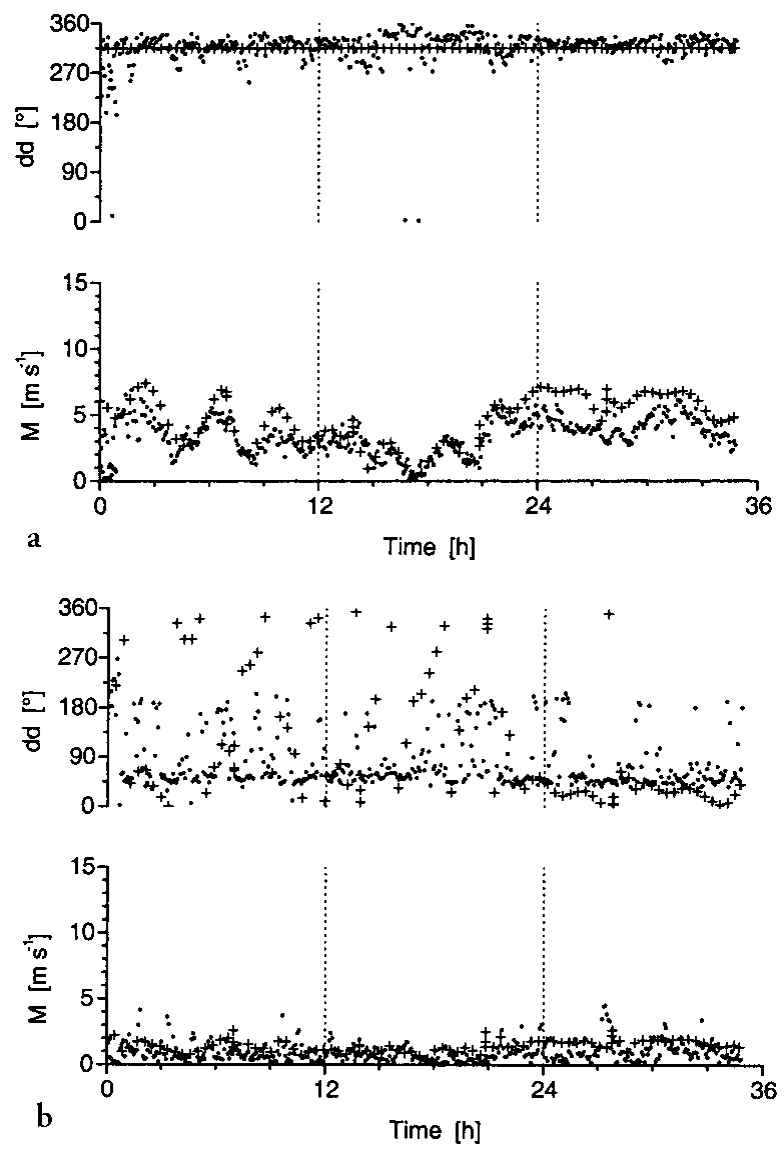

Fig. 9. Comparison of the wind-field simulation $(+)$ with the corresponding measurements ( $\cdot ; 5$ min averages). (a) Windward side of the crest (M76); (b) leeward side of the crest (M73/74). 
lation also reflects the wind direction at that mast quite well. Considering that wind-flow modeling for the severe complex topography of Alpine environments is still a topic of research, the simulated wind field gives reasonable results. Comparisons at the other masts and different heights, not shown here, confirm this.

So far, there is no suitable method available for measuring the snow depth over an extended area with reasonable effort and good accuracy. In our case, the required accuracy is better than $\pm 0.1 \mathrm{~m}$, which is of the same order as the newsnow depth during a typical drift period in winter 1996/97. Hence, the simulation and field measurements were compared for a small area (about $200 \times 40 \mathrm{~m}^{2}$ ) around the crest.

Figure 10a shows the cross-section of profile line 3, which connects masts M76, M75 and M74/73 as indicated. Depicted is the topography used in the grid and, for comparison, the topography given by the digital map (DHM). Although the grid represents the crest quite well, it is obviously smoother than the DHM and even the real topography. Figure 10b compares the measured and simulated new-snow depth for the precipitation period 19-21 March. One can see a high variability in the measurements, partly influenced by the topography, partly due to small moving dunes. The simulation shows reasonable agreement with the measurements. The largest deviation was found on the windward slope just behind the small depression. A possible explanation for this deviation is given below.

An example of a spatial comparison is shown in Figure 11. To reduce the variability due to varying snowpack properties and the turbulent character of the wind, present in the individual measurements, and to highlight the more characteristic deposition features, an average over all six measured storm episodes was calculated. For the simulation, a "model" period was chosen. The comparison between both appears to be justified since it is claimed that the simulated model episode is prototypical of the storm episodes of winter 1996/97.

The measurements still show some variability, but also

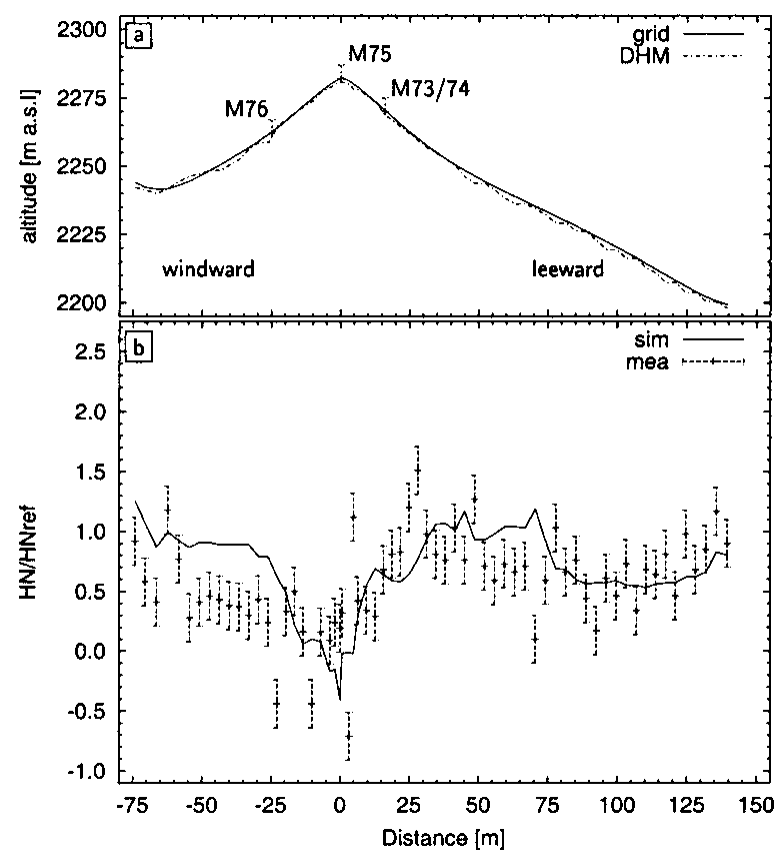

Fig. 10. (a) Cross-section of the topography at profile line 3. Depicted is the topography used in the grid, and for comparison the topography given by the digital map (DHM). (b) Comparison between the measured and simulated new-snow depth for the precipitation period 19-21 March. some trends can be discerned: one can see the erosion area in the windward slope near the crest line, the formation of a cornice at the ridge, and an area just leeward of the crest where the snow depth is less than the reference depth. Downslope areas where $\mathrm{HN}$ is twice $\mathrm{HN}_{\text {ref }}$ alternate with depletion areas such as the small terrace on the right. It should be recognized that the small-scale terrain features can cause large differences in the erosion and deposition patterns. The simulation does not show the same variability, but nevertheless reproduces some characteristic features such as the windward erosion area close to the crest, alternation between depleted areas and areas of enhanced deposition. As well as the uncertainties due to the poorly known snowpack properties (e.g. the critical shear stress), another reason for the discrepancy between the measurements and the simulation can be found in the history of the snowpack evolution. Thus,
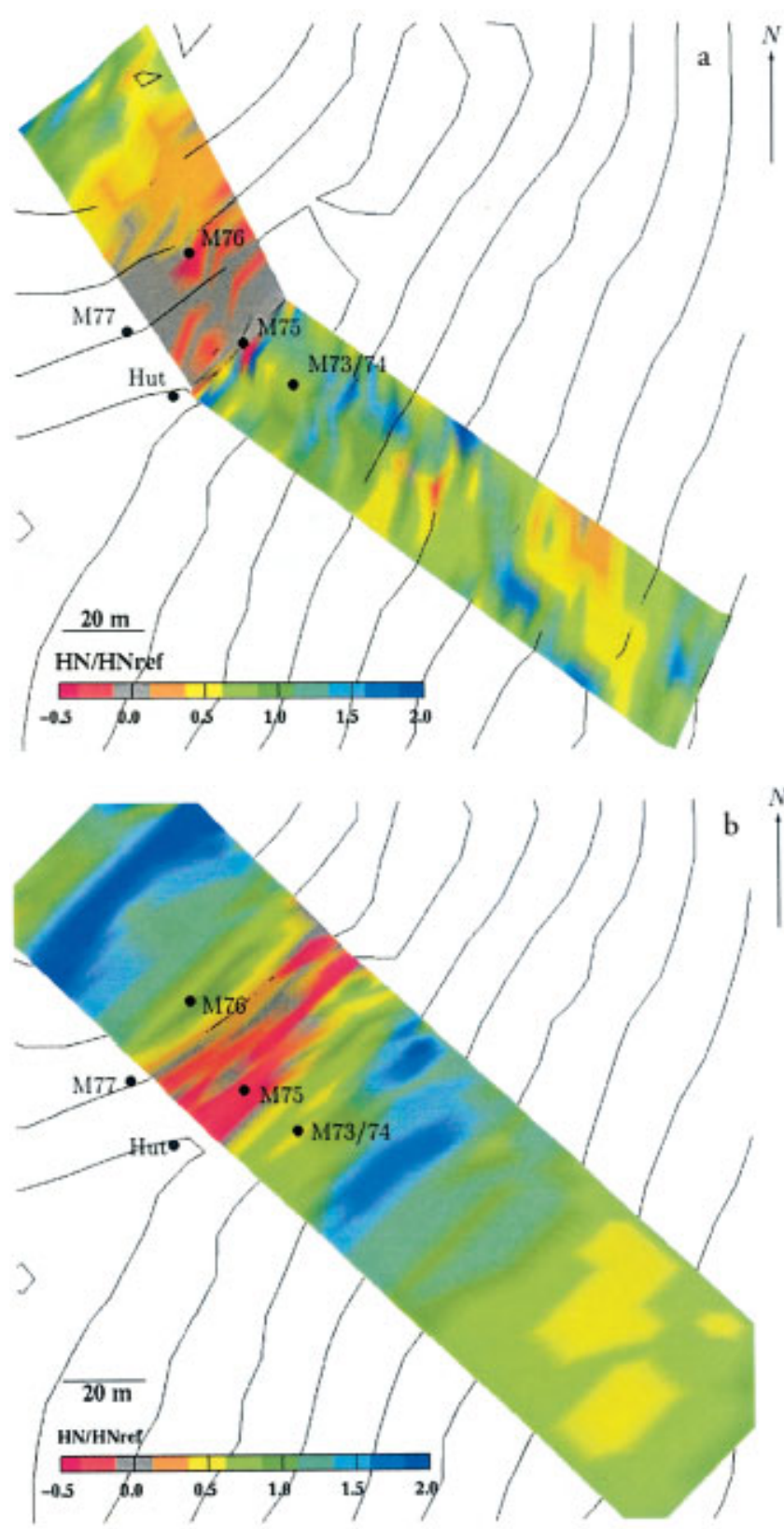

Fig. 11. Comparison between soundings and simulated redistribution pattern for a small area around Gaudergrat ridge. Shown are the normalized new-snow depths; negative values indicate erosion of the old snowpack (contour interval is $10 \mathrm{~m})$. (a) Measured new-snow depths $\left(\mathrm{HN}_{\mathrm{ref}}=2.53 \mathrm{~m}\right.$; all six drift episodes are combined. (b) Simulation $\left(\mathrm{HN}_{\mathrm{ref}}=0.48 \mathrm{~m}\right.$; after $\left.t \approx 70 \mathrm{~h}\right)$. 

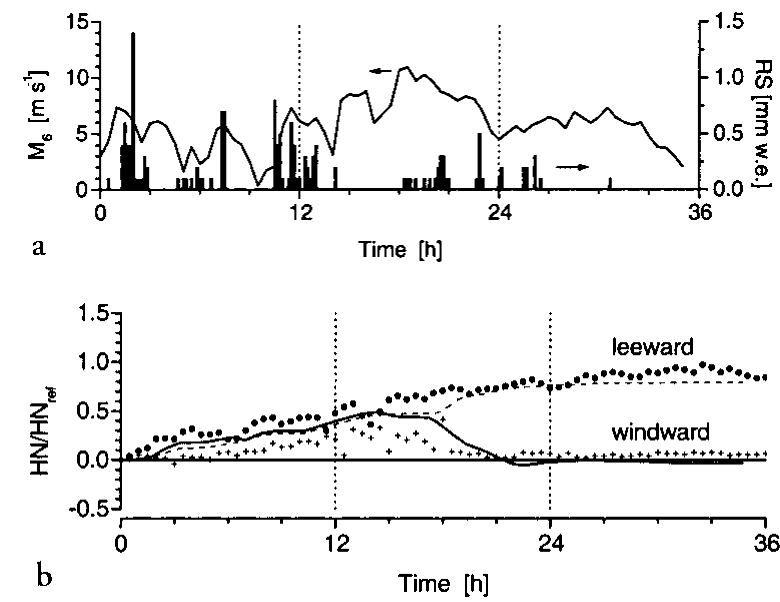

Fig. 12. (a) Wind speed, $M(z=6 \mathrm{~m})$ (30 min averages), at the top of the crest (M75) and the precipitation rate, $R S$ (10 min sum); wind direction, $d d \approx 315^{\circ}$ (northwest). (b) Temporal evolution of the normalized new-snow depth at the points M77 (windward) and M74 (leeward). (Lines denote simulation and markers are measurements.)

snowdrift tends to fill in hollows and to even out the topography in the course of a winter until an equilibrium level of the snow surface is reached where erosion balances deposition. This phenomenon could explain the discrepancy in the depression throughout the windward slope, particularly if the initially measured snow depth at this location was already close to its equilibrium level, whereas for the simulation a uniform initial snow depth was assumed. Thus the simulation might tend to deposit more snow as expected until the equilibrium level is reached. Nevertheless, the results of the simulation give reasonable images.

Another kind of comparison is shown in Figure 12b, which depicts the measured temporal evolution of the new snow at points M77 and M74/73 (windward and leeward of the crest; both masts were equipped with ultrasonic snowdepth sensors) during a drift episode, and the corresponding simulation. This comparison shows that, despite the rough estimates of the snowpack properties, the model can reproduce the temporal evolution of the snow depth quite well. Figure $12 \mathrm{a}$ depicts the corresponding wind speed at the top of the crest, and the precipitation rate.

Finally, Figure 13 depicts an example of the simulated redistribution pattern of the new-snow layer for the whole simulated area. The new snow is picked up in acceleration regions such as the area close to the crest line, and at small humps and brows. At the crest line, erosion of the old snowpack is observed as well. Deposition occurs in the deceleration regions leeward of the saddle, in small gullies and in hollows. In this simulation, depositions twice the reference height and erosion depth of about $0.1 \mathrm{~m}$ of the old snowpack are found at the crest line. The simulation gives a reasonable image of the redistribution pattern, which tallies with the observations in the field (see, e.g., Fig. 14).

\section{CONCLUDING REMARKS}

The present model is a step toward accurate numerical simulation of blowing and drifting snow in Alpine terrain. The primary emphasis was on a physically based description of snowdrift suitable for complex Alpine terrain. The model includes: a fully three-dimensional non-steady-state model-

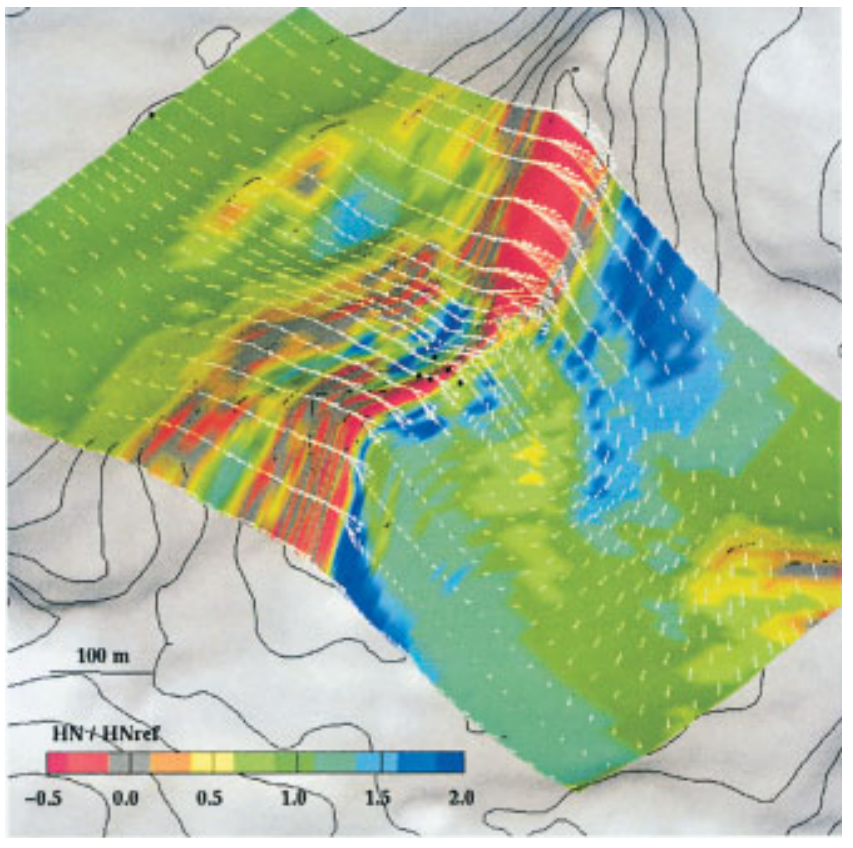

Fig. 13. Simulated snow distribution. The snow depth is normalized by the reference new-snow depth; negative values indicate erosion of the old snowpack. $\left(\mathrm{HN}_{\mathrm{ref}}=0.48 \mathrm{~m}\right.$; after $t \approx$ 70 h.) The arrows indicate the simulated wind field for a typical situation approximately $2 m$ above ground.

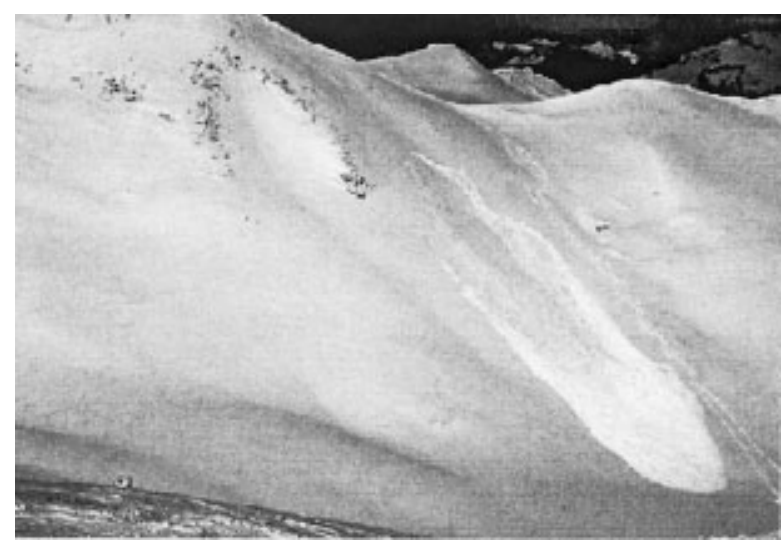

Fig. 14. Slab avalanche at Gaudergrat. The photo was taken on 21 February 1997 after a precipitation period with snowdrift. It shows the saddle and the gully visible in Figure 13, northeast of experimental site.

ing; the modeling of the two main transport modes (saltation and suspension); the dynamical modeling of deposition and erosion, distinguishing between aerodynamic entrainment and ejecta due to particle impacts; the back-reaction of the particles in saltation on the flow (two-way coupling); and the adaptation of the grid to changing snow heights. The comparison between simulations and field measurements is encouraging and indicates that numerical simulations of snowdrift may develop into a powerful tool for land-use planning and avalanche forecasting.

On the other hand, the first numerical simulations also demonstrate the problems with models involving complex terrain. For example, the grid resolution must match the length scale of the terrain. In an early simulation, the simulated wind field differed significantly from the measurements, and the $25 \mathrm{~m}$ resolution of the available digital terrain model of the Gaudergrat experimental site proved to be insufficient to resolve key topographic features, like the sharp crest line, in a reasonable way. Special effort had been undertaken to improve the terrain model and thus the numerical 
grid in the region of interest close to the crest line. A critical point in wind-transport simulation is the non-linear increase of the computational effort with increase of the area of interest and/or spatial resolution of the area. At that point, a compromise must be made between a high spatial resolution and an acceptable computational effort.

Poorly known boundary conditions are a common problem for wind-field simulations in Alpine terrain. To overcome this problem, one might consider using the output of a mesoscale weather model. Some of these models are under development, but are not yet fully adapted for use in mountain areas.

How mechanical properties of the snowpack affect snowdrift rates is still unknown. It is reasonable to expect parameters like erodibility, the rebound probability of particles, the energy loss during impact, the rebound angle, etc., to differ for different snow types, but no systematic investigation has been carried out to study these relationships as yet. The present parameterization of erosion and deposition used in the model is mainly based on wind-tunnel studies and numerical simulations for aeolian particle transport. However, it is possible to include the dependency on varying mechanical snowpack properties into the model. For that, some research will be necessary to determine these mechanical properties for the varying conditions occurring in nature. This research should include cold-room wind-tunnel studies, similar to those done for aeolian particle transport, using different snow types.

Another still poorly known process is the mutual influence between particle transport and turbulence structure of the airflow within the boundary layer (surface layer) (e.g. the modification of saltation, transition to suspension, or damping of the turbulence). To this end, it would be of interest to do instantaneous profile measurements of the mass flux and the wind speed close to the surface with high temporal resolutions. With improving sensor technology this becomes more and more possible.

\section{ACKNOWLEDGEMENTS}

This research was funded by the Swiss Federal Office of Education and Science under the contract OFES 93.0082 as part of the European "Human Capital and Mobility" project "Contribution to avalanche dynamics with the aim of mapping hazardous areas", contract CE CHRX-CT 93-0307. I thank D. Issler and P. Föhn for many enjoyable discussions, and B. Brown for his comments. I am also indebted to W. Ammann, C. Fierz, M. Hiller, G. Klausegger, G. Krüsi, R. Meister and P.Weilenmann, as well as the staff of the mechanical workshop, for help in preparing the field measurements. Similarly, I am grateful to C. Camponovo, S. Harvey, C. Marty, R. Mullins, M. Phillips and K. Plattner for their assistance in the field, to A. Stoffel for his geographic information system support and to B. Gauderon for his support on computer-related questions. I also thank the editors, two unknown reviewers and L. McKittrick for their comments.

\section{REFERENGES}

AEA Technology. 1995. CFX-4.1: flow solver user guide. Oxford, AEA Technology. Anderson, R. S. and P. K. Haff. 1988. Simulation of eolian saltation. Science, 241, 820-823.

Anderson, R. S. and P. K. Haff. 1991. Wind modification and bed response during saltation of sand in air. Acta Mech., Supplementum 1. Aeolian Grain Transport. 1: Mechanics, 21-52.

Anderson, R. S., M. Sørensen and B. B. Willets. 1991. A review of recent pro- gress in our understanding of aeolian sediment transport. Acta Mech., Supplementum 1. Aeolian Grain Transport. 1: Mechanics, 1-19.

Anno, Y. 1985. Modelling a snowdrift by means of activated clay particles. Ann. Glaciol., 6, 48-52.

Bagnold, R. A. 1954. The physics of blowing sand and desert dunes. Second edition. London, Methuen.

Castelle, T. 1995. Transport de la neige par le vent en montagne: approche expérimentale du site du Col du Lac Blanc. (Thèse de doctorat, École Polytechnique Fédérale de Lausanne.) (Thèse 1303, 1994.)

Clift, R., J. R. Grace and M. E. Weber. 1978. Bubbles, drops and particles. London, Academic Press Inc.

Föhn, P. M. B. 1980. Snow transport over mountain crests. f. Glaciol., 26(94), 469-480.

Föhn, P. M. B. and R. Meister. 1983. Distribution of snow drifts on ridge slopes: measurements and theoretical approximations. Ann. Glaciol., 4, $52-57$.

Gauer, P. 1999. Blowing and drifting snow in Alpine terrain: a physicallybased numerical model and related field measurements. Eidg. Inst. Schnee- und Lawinenforsch. Mitt. 58.

Gubler, H. 1982. Strength of bonds between ice grains after short contact times. F. Glaciol., $28(100), 457-473$.

Guyomarc'h, G. and L. Mérindol. 1998. Validation of an application for forecasting blowing snow. Ann. Glaciol., 26, 138-143.

Iversen, J. D. 1980. Wind tunnel modeling of snow fences and natural snow fence controls. Proc. East. Snow Conf., 37th Annual Meeting, 5-6 June 1980. Peterborough, Ont., Canada, 106-124.

Jackson, P. S. 1981. On the displacement height in the logarithmic velocity profile. 7. Fluid Mech., 111, 15-25.

Kobayashi, D. 1972. Studies of snow transport in low-level drifting snow. Contrib. Inst. Low Temp. Sci., Ser. A 24.

Kosugi, K., K. Nishimura and N. Maeno. 1995. Studies on the dynamics of saltation in drifting snow. Rep. Natl. Res. Inst. Earth Sci. Disaster Prev. 54, $111-154$.

Li, L. and J.W. Pomeroy. 1997. Estimates of threshold wind speeds for snow transport using meteorological data. 7. Appl. Meteorol., 36 (3), 205-213.

Liston, G. E. and M. Sturm. 1998. A snow-transport model for complex terrain. 7. Glaciol., 44(148), 498-516.

Liston, G. E., R. L. Brown and J. D. Dent. 1993. Application of the $E-\varepsilon$ turbulence closure model to separated atmospheric surface layer flows. Boundary-Layer Meteorol., 66(3), 281-301.

Maeno, N., K. Araoka, K. Nishimura and Y. Kaneda. 1979. Physical aspects of the wind-snow interaction in blowing snow. F. Fac. Sci., Hokkaido Univ., Ser. 7, Geophys., 6(1), 127-141.

Maeno, N. and 8 others. 1985. Wind-tunnel experiments on blowing snow. Ann. Glaciol., 6, 63-67.

Maeno, N., K. Nishimura, K. Sugiura and K. Kosugi. 1995. Grain size dependence of eolian saltation lengths during snow drifting. Geophys. Res. Lett., 22(15), 2009-2012.

Mases, M., L. Buisson and W. Frey. 1995. Modélisation de la répartition spatiale de la neige transportée par le vent dans le système ELSA. In Sivardière, F., ed. Les apports de la recherche scientifique à la sécurité neige, glace et avalanche. Actes de Colloque, Chamonix 30 mai-3 juin 1995. Grenoble, Association Nationale pour l'Étude de la Neige et des Avalanches (ANENA), 49-54.

Masselot, A. and B. Chopard. 1998. A lattice Boltzmann model for snow transport and deposition. Europhys. Lett., 42(3), 259-264.

McEwan, I. K. and B. B. Willets. 1991. Numerical model of the saltation cloud. Acta Mech., Supplementum 1. Aeolian GrainTransport. 1: Mechanics, 53-66.

McEwan, I. K. and B. B. Willets. 1993. Sand transport by wind: a review of the current conceptual model. In Pye, K., ed. The dynamics and environmental context of aeolian sedimentary systems. London, Geological Society of London, 7-16. (Special Publication 72.)

Meister, R. 1987. Wind systems and snow transport in Alpine topography. International Association of Hydrological Sciences Publication 162 (Symposium at Davos 1986 - Avalanche Formation, Movement and Effects), 265-278.

Mellor, M. and G. Fellers. 1986. Concentration and flux of wind-blown snow. CRREL Spec. Rep. 86-11.

Naaim, M., F. Naaim-Bouvet and H. Martinez. 1998. Numerical simulation of drifting snow: erosion and deposition models. Ann. Glaciol., 26, 191-196.

Nishimura, K., K. Sugiura, M. Nemoto and N. Maeno. 1998. Measurements and numerical simulations of snow-particle saltation. Ann. Glaciol., 26, 184-190.

Owen, P. R. 1964. Saltation of uniform grains in air. 7. Fluid Mech., 20(2), 225-242.

Pichler, H. 1986. Dynamik der Atmosphäre. Second edition. Mannheim, etc., Bibliographisches Institut.

Pomeroy, J.W. 1989. A process-based model of snow drifting. Ann. Glaciol., 13, $237-240$.

Pomeroy, J.W. and D. M. Gray. 1990. Saltation of snow. Water Resour. Res., 26(7), 1583-1594. 
Pope, M. Unpublished. Particle size and mass distribution in Alpine windblown snow. Weissfluhjoch/Davos, Eidgenössische Institut für Schnee- und Lawinenforschung. (Interner Bericht 567.)

Radok, U. 1977. Snow drift. F. Glaciol., 19(81), 123-139.

Rasmussen, K. R., M. Sørensen and B. B. Willets. 1985. Measurement of saltation and wind strength on beaches. In Barndorff-Nielsen, O. E., ed. International Workshop on the Physics of Blown Sand. Proceedings. Vol. 2. Aarhus, University of Aarhus. Institute of Mathematics. Department of Theoretical Statistics, 301-325. (Mem. 8.)

Rice, M. A., B. B. Willets and I. K. McEwan. 1995. An experimental study of multiple-grain-size ejecta produced by collisions of saltating grains with a flat bed. Sedimentology, 42, 695-706.

Rice, M. A., B. B. Willets and I. K. McEwan. 1996. Observations of collisions of saltating grains with a granular bed from high-speed cine-film. Sedimentology, 43, 21-31

Rodi, W. 1980. Turbulence models and their application on hydraulics. Delft, International Association for Hydraulic Research. (State-of-the-art paper.)

Sato, T., T. Uematsu and Y. Kaneda. 1997. Application of a random walk model to blowing snow. In Izumi, M., T. Nakamura and R. L. Sack, eds. Snow engineering: recent advances. Rotterdam, A. A. Balkema, 133-138.

Schmidt, D. S., J. D. Dent and R. A. Schmidt. 1998. Charge-to-mass ratio of individual blowing-snow particles. Ann. Glaciol., 26, 207-211.

Schmidt, R. A. 1980. Threshold wind-speeds and elastic impact in snow transport. f. Glaciol., 26(94), 453-467.

Schmidt, R.A. 1982. Vertical profiles of wind speed, snow concentration and humidity in blowing snow. Boundary-Layer Meteorol., 23(2), 223-246.

Schmidt, R. A. 1984. Measuring particle size and snowfall intensity in drifting snow. Cold Reg. Sci. Technol., 9(2), 121-129.

Schmidt, R. A. 1986. Transport rate of drifting snow and the mean wind speed profile. Boundary-Layer Meteorol., 34(3), 213-241.
Schmidt, R. A., R. Meister and H. Gubler. 1984. Comparison of snow drifting measurements at an Alpine ridge crest. Cold Reg. Sci. Technol., 9(2), 131-141.

Shaw, R. H. and A. R. Pereira. 1982. Aerodynamic roughness of a plant canopy: a numerical experiment. Agric. Met., 26, 51-65.

Sørensen, M. 1991. An analytic model of wind-blown sand transport. Acta Mech., Supplementum 1. Aeolian Grain Transport. 1: Mechanics, 67-81.

Stull, R. B. 1997. An introduction to boundary laver meteorology. Second edition. Dordrecht, etc., Kluwer Academic Publishers. (Atmospheric Sciences Library.)

Sundsbø, P.-A. and E. W. M. Hansen. 1997. Modelling and numerical simulation of snow drift around snow fences. In Izumi, M., T. Nakamura and R. L. Sack, eds. Snow engineering: recent advances. Rotterdam, A. A. Balkema, 353-359.

Takeuchi, M. 1980. Vertical profile and horizontal increase of drift-snow transport. 7. Glaciol., 26(94), 481-492.

Thom, A. S. 1971. Momentum absorption by vegetation. Q. F. R. Meteorol. Soc., 97, 414-428.

Uematsu, T. 1993. Numerical study on snow transport and drift formation. Ann. Glaciol., 18, 135-141.

Uematsu, T., Y. Kaneda, K. Takeuchi, T. Nakata and M. Yukumi. 1989. Numerical simulation of snowdrift development. Ann. Glaciol., 13, 265-268.

Werner, B. 1990. A steady state model of wind-blown sand transport. F. Geol., $98(1), 1-17$.

Werner, B. T. and P. K. Haff. 1988. The impact process in aeolian saltation: two-dimensional simulations. Sedimentology, 35, 189-196.

Wieringa, J. 1993. Representative roughness parameters for homogeneous terrain. Boundary-Layer Meteorol., 63(4), 323-363.

Willets, B. B. and M. A. Rice. 1985. Inter-saltation collisons. In BarndorffNielsen, O. E., ed. International Workshop on the Physics of Blown Sand. Proceedings. Vol. 1. Aarhus, University of Aarhus. Institute of Mathematics, 83-100. (Mem. 8.)

MS received 12 April 1999 and accepted in revised form 10 November 2000 